University of South Florida

DIGITAL COMMONS

Digital Commons @ University of

@ UNIVERSITY OF SOUTH FLORIDA

South Florida

Research Reports

National Center for Transit Research (NCTR)

Archive (2000-2020)

$1-1-2012$

\title{
Estimating Costs and Benefits of Emissions Reduction Strategies for Transit by Extending the TRIMMS Model
}

CUTR

Follow this and additional works at: https://digitalcommons.usf.edu/cutr_nctr

\section{Recommended Citation}

"Estimating Costs and Benefits of Emissions Reduction Strategies for Transit by Extending the TRIMMS Model," National Center for Transit Research (NCTR) Report No. CUTR-NCTR-RR-2011-01, Center for Urban Transportation Research, University of South Florida, 2012.

DOI: https://doi.org/10.5038/CUTR-NCTR-RR-2011-01

Available at: https://scholarcommons.usf.edu/cutr_nctr/124

This Technical Report is brought to you for free and open access by the National Center for Transit Research (NCTR) Archive (2000-2020) at Digital Commons @ University of South Florida. It has been accepted for inclusion in Research Reports by an authorized administrator of Digital Commons @ University of South Florida. For more information, please contact digitalcommons@usf.edu. 


\section{National Center} for Transit Research

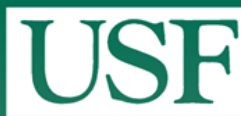

UNIVERSITY OF

SOUTH FLORIDA

Estimating Costs and Benefits of Emissions Reduction Strategies for Transit by Extending the TRIMMS Model

January 2012

Final Report

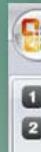
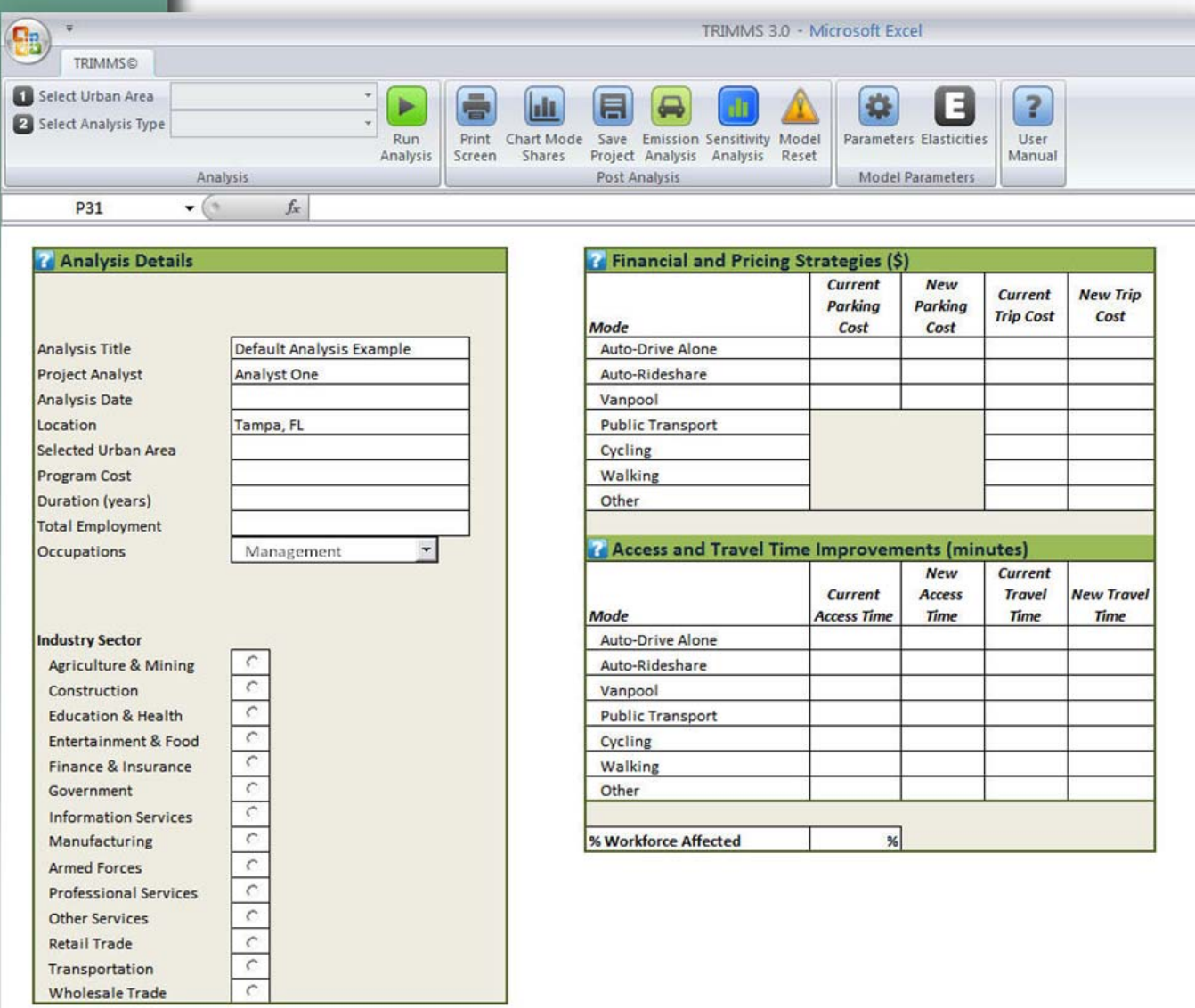

\begin{tabular}{|c|c|c|c|c|}
\hline \multicolumn{5}{|c|}{ Financial and Pricing Strategies (\$) } \\
\hline Mode & $\begin{array}{l}\text { Current } \\
\text { Parking } \\
\text { Cost }\end{array}$ & $\begin{array}{c}\text { New } \\
\text { Parking } \\
\text { Cost }\end{array}$ & $\begin{array}{l}\text { Current } \\
\text { Trip Cost }\end{array}$ & $\begin{array}{c}\text { New Trip } \\
\text { Cost }\end{array}$ \\
\hline \multicolumn{5}{|l|}{ Auto-Drive Alone } \\
\hline \multicolumn{5}{|l|}{ Auto-Rideshare } \\
\hline \multicolumn{5}{|l|}{ Vanpool } \\
\hline \multicolumn{5}{|l|}{ Public Transport } \\
\hline \multicolumn{5}{|l|}{ Cycling } \\
\hline \multicolumn{5}{|l|}{ Walking } \\
\hline \multicolumn{5}{|l|}{ Other } \\
\hline \multicolumn{5}{|c|}{ 7. Access and Travel Time Improvements (minutes) } \\
\hline Mode & $\begin{array}{c}\text { Current } \\
\text { Access Time }\end{array}$ & $\begin{array}{c}\text { New } \\
\text { Access } \\
\text { Time }\end{array}$ & $\begin{array}{l}\text { Current } \\
\text { Travel } \\
\text { Time }\end{array}$ & $\begin{array}{c}\text { New Travel } \\
\text { Time }\end{array}$ \\
\hline \multicolumn{5}{|l|}{ Auto-Drive Alone } \\
\hline \multicolumn{5}{|l|}{ Auto-Rideshare } \\
\hline \multicolumn{5}{|l|}{ Vanpool } \\
\hline \multicolumn{5}{|l|}{ Public Transport } \\
\hline \multicolumn{5}{|l|}{ Cycling } \\
\hline \multicolumn{5}{|l|}{ Walking } \\
\hline \multicolumn{5}{|l|}{ Other } \\
\hline \% Workforce Affected & $\%$ & & & \\
\hline
\end{tabular}

Funded by

Florida Department of Transportation

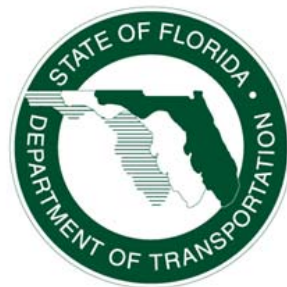

Contract Number BDK85 977-27 


\section{DISCLAIMER}

The contents of this report reflect the views of the authors, who are responsible for the facts and the accuracy of the information presented herein. This document is disseminated under the sponsorship of the Department of Transportation University Transportation Centers Program and the Florida Department of Transportation, in the interest of information exchange. The U.S. Government and the Florida DOT assume no liability for the contents or use thereof. 


\section{Estimating Costs and Benefits of Emissions Reduction Strategies for Transit by Extending the TRIMMS Model}

Final Report

Contract No. BDK85 977-27

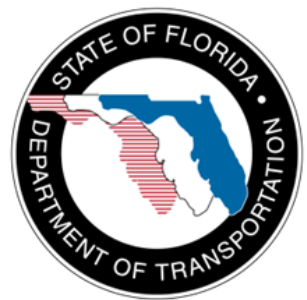

January 2012

FDOT Project Manager:

Amy Datz

Report prepared by:

Sisinnio Concas, Ph.D.

Philip L. Winters

Center for Urban Transportation Research

University of South Florida, College of Engineering

4202 E. Fowler Ave., CUT100, Tampa, FL 33620-5375 


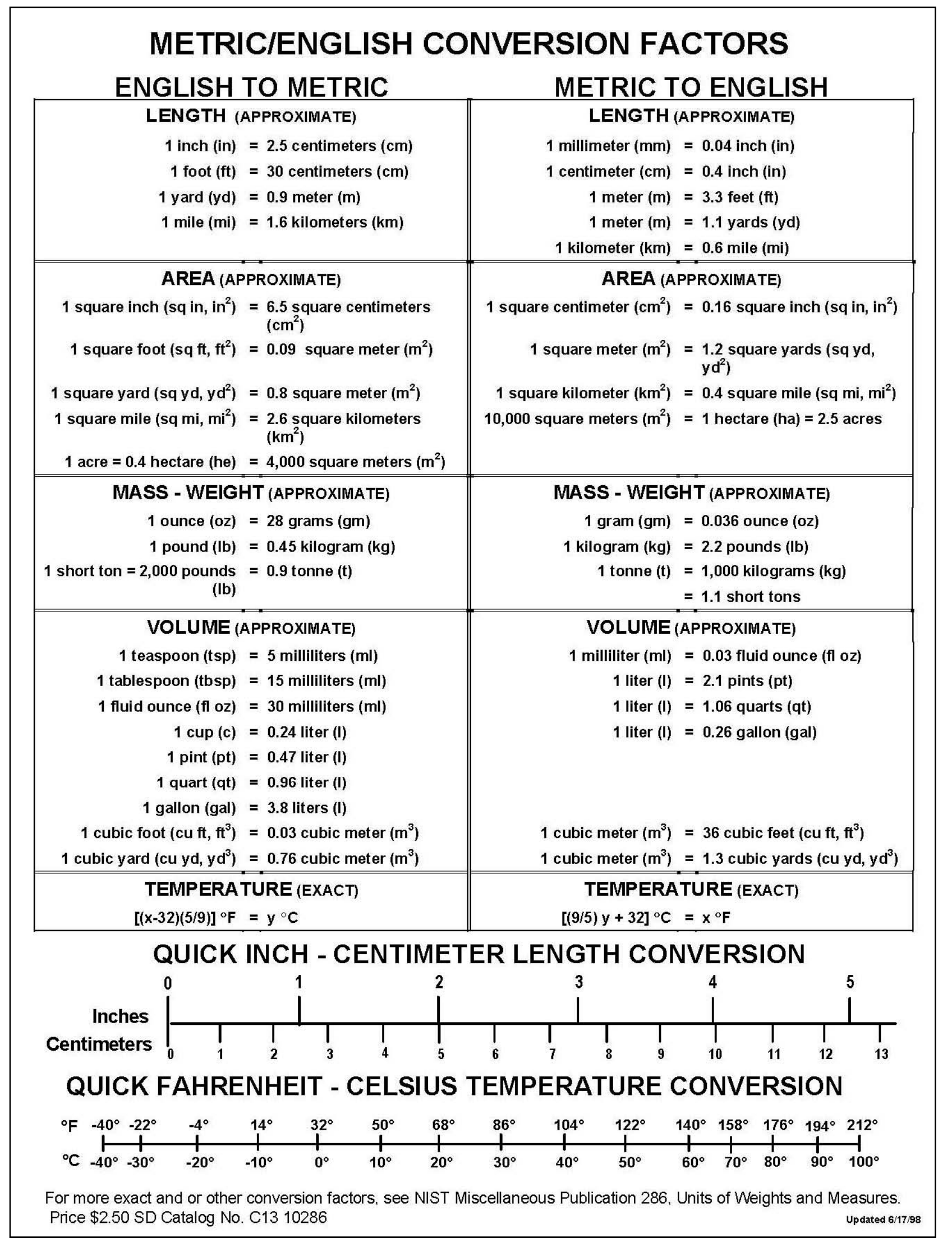




\section{Technical Report Documentation Page}

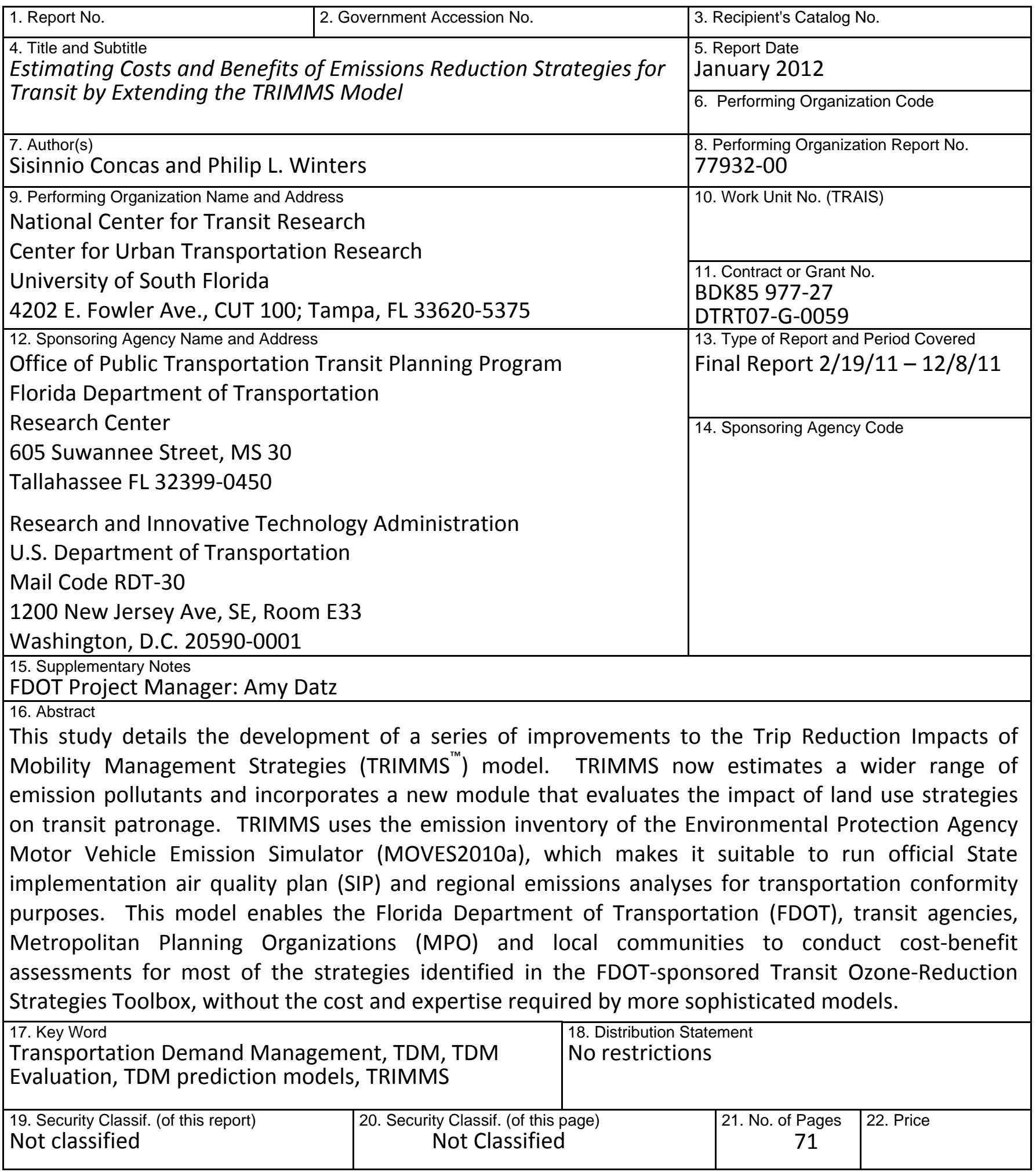

Form DOT F 1700.7 (8-72) Reproduction of completed page authorized 


\section{Table of Contents}

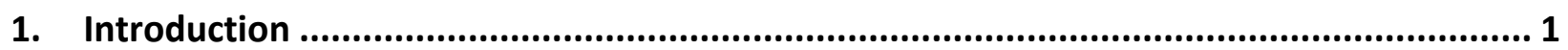

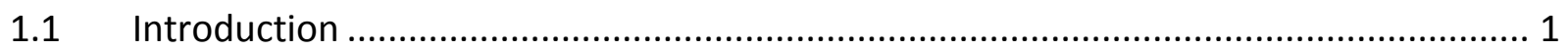

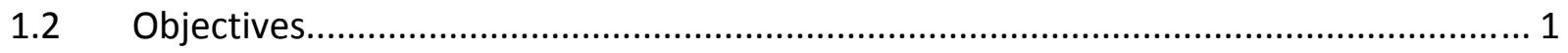

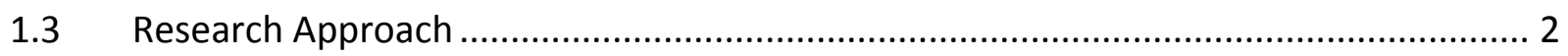

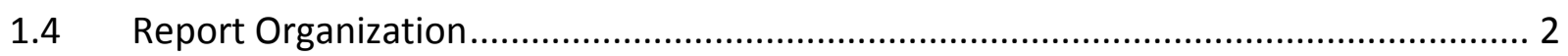

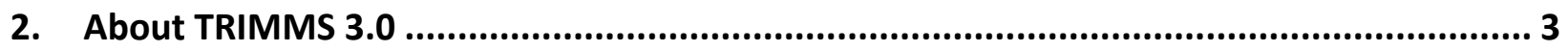

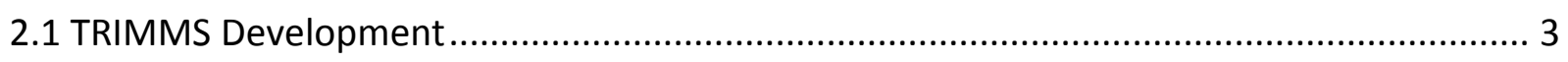

2.2 New or Updated Features of Version 3.0 ………................................................... 5

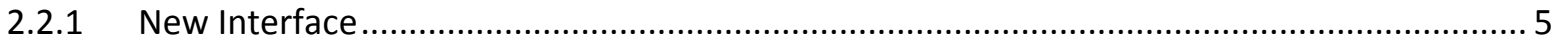

2.2.2 Comprehensive Emission Analysis .............................................................................. 6

2.2.4 Land Use Impacts .............................................................................................. 7

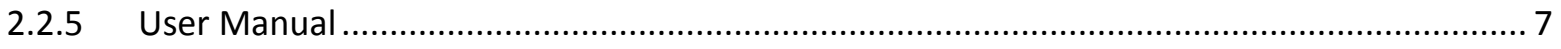

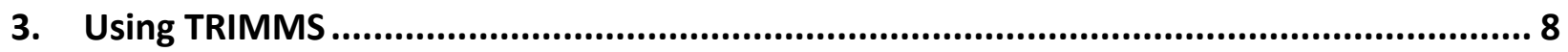

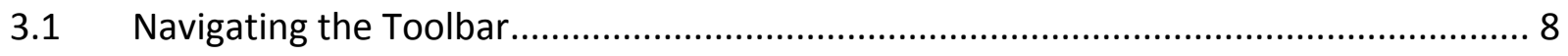

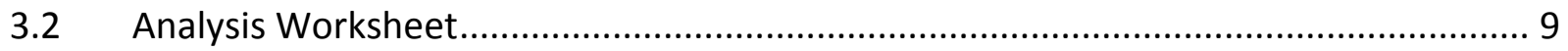

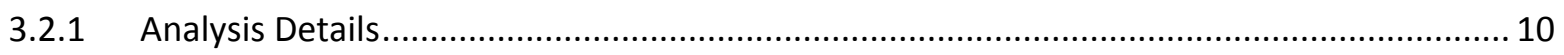

3.2.2 Employer-Based Commuter Programs............................................................................ 12

3.2.3 Strategies Affecting Travel Costs and Travel Times ........................................................... 14

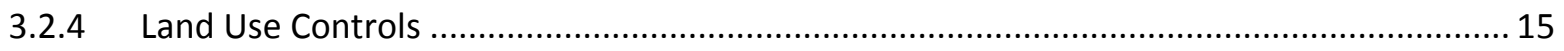

3.3 Results Worksheet .......................................................................................... 16

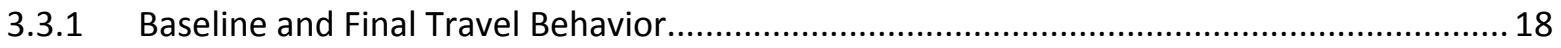




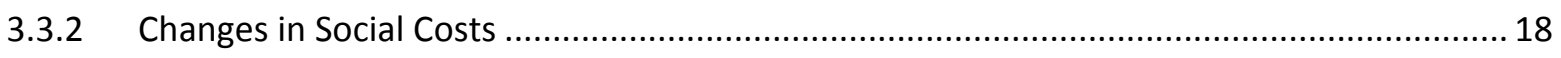

3.3.4 Changes in Air Pollution Emissions Costs ....................................................................... 19

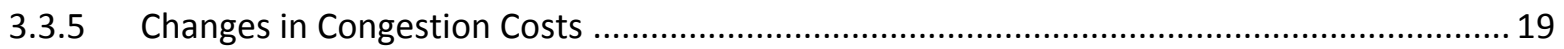

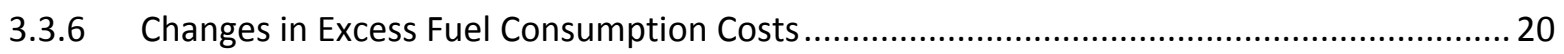

3.3.7 Changes in Global Climate Change Costs ......................................................................... 20

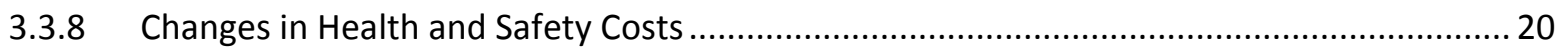

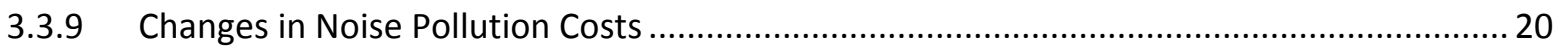

P. Program Cost Effectiveness ............................................................................ 21

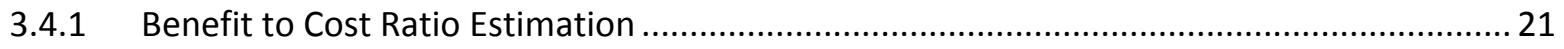

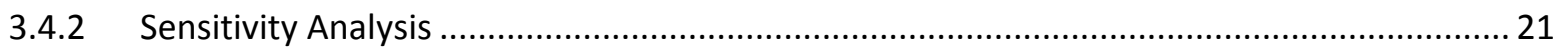

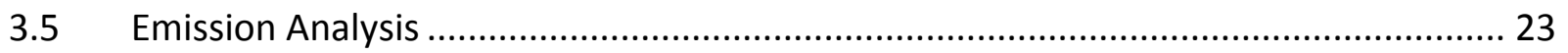

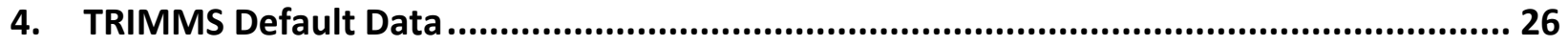

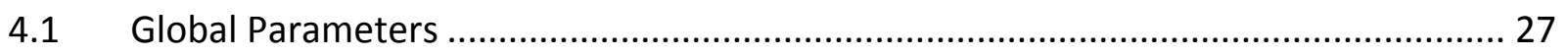

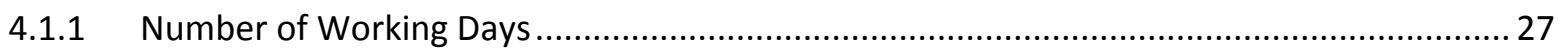

4.1.2 U.S. Median Household Income and Population Density .................................................. 27

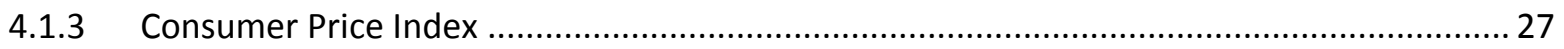

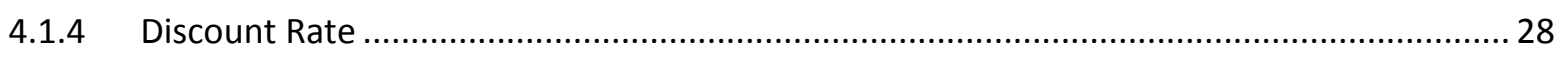

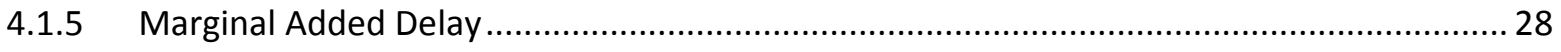

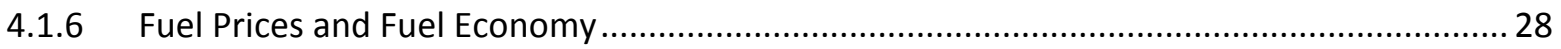

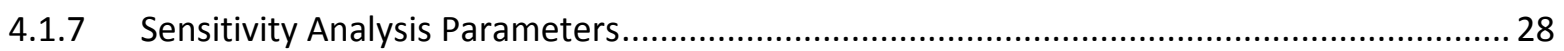

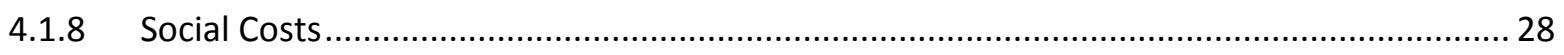

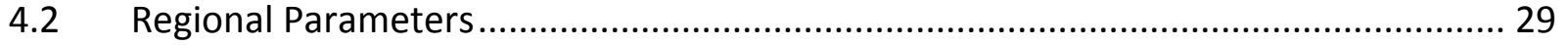

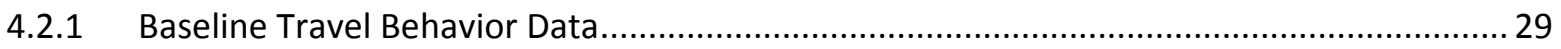

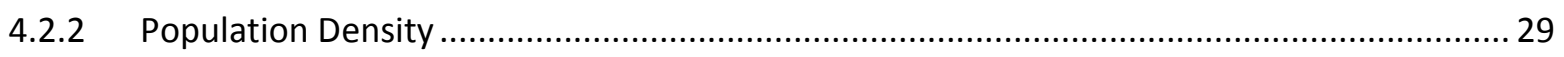

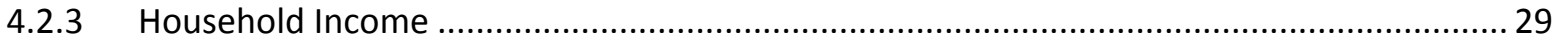

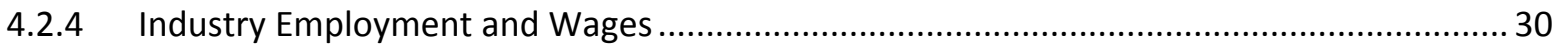

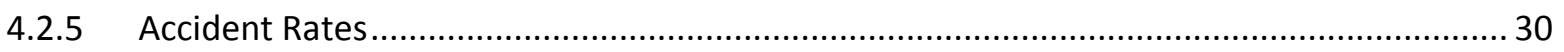

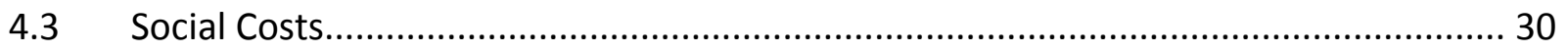

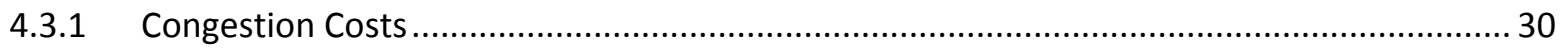

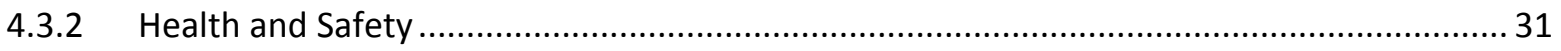




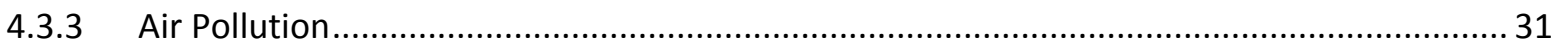

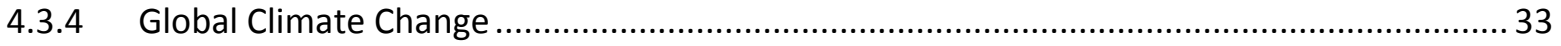

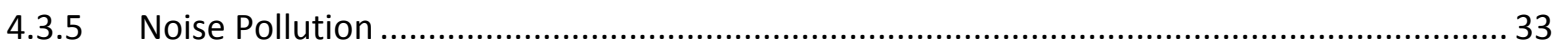

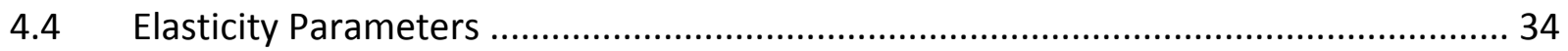

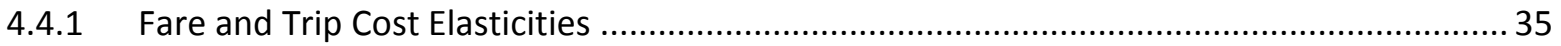

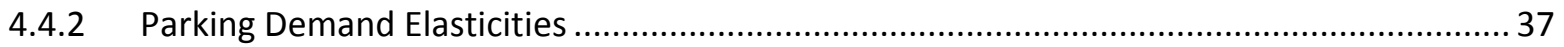

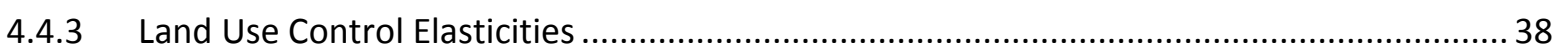

5. Transit Ozone-Reduction Toolbox: Strategies Evaluated by TRIMMS............................. 40

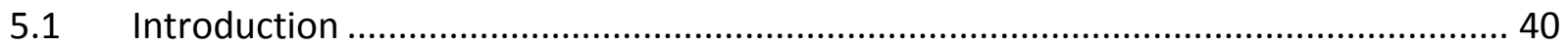

5.2 Using TRIMMS to Evaluate Ozone-Reduction Strategies ...................................... 40

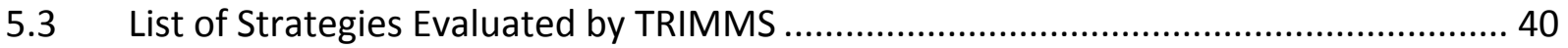

5.4 Comprehensive Evaluation of Emission Reduction Strategies ................................. 44

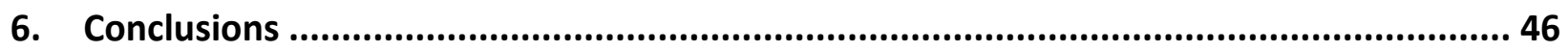

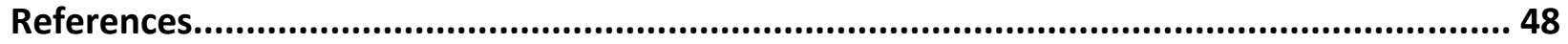

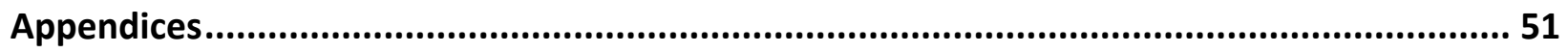

A.1 Constant Elasticity of Substitution Trip Demand Functions ................................... 52

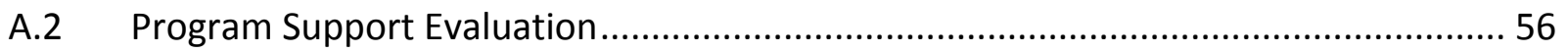

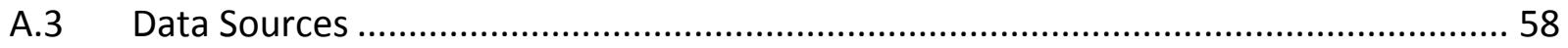




\section{List of Tables}

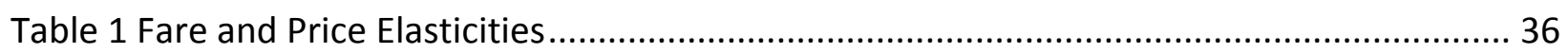

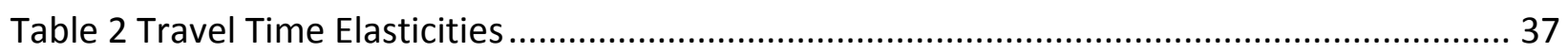

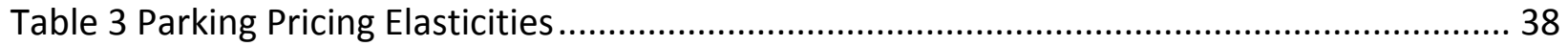

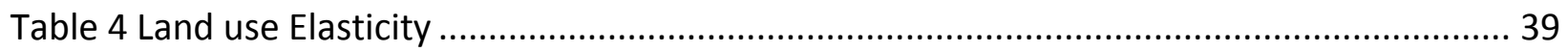

Table 5 Transit Ozone-Reduction Strategies Evaluated by TRIMMS ...................................... 42

Table 6 Emission Reductions For Selected Pollutants: EPA National TCM Policy Evaluation ...... 45

\section{List of Figures}

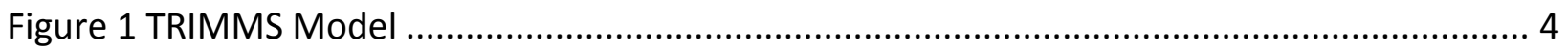

Figure 2 TRIMMS and Microsoft Excel Ribbon Toolbar ....................................................... 6

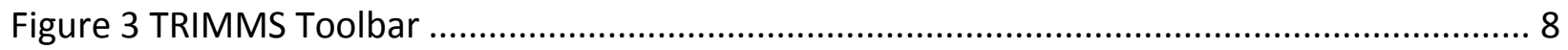

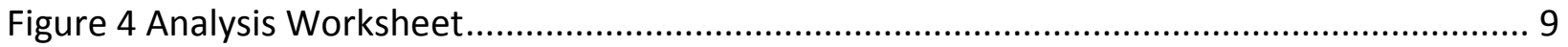

Figure 5 Site-Specific Analysis Industry Sector Options................................................... 11

Figure 6 Area-Wide Analysis Industry Sector Options ........................................................... 12

Figure 7 Employer-Based Commuter Programs Evaluation .................................................... 13

Figure 8 Strategies Affecting Travel Costs and Travel Times ............................................... 15

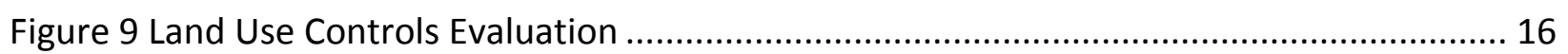

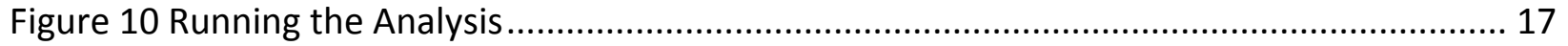

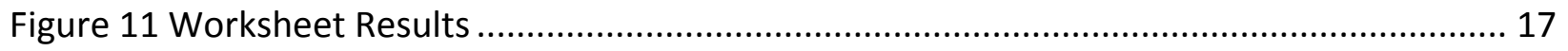

Figure 12 Change in Travel Behavior (Final Estimates vs. Baseline Data) ................................ 18

Figure 13 Impact on SOV Travel and in Social Costs............................................................ 19

Figure 14 Net Program Benefits and Benefit-to-Cost Ratio ................................................. 21

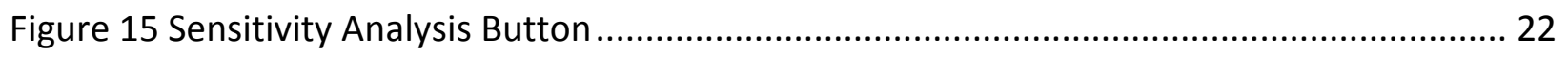

Figure 16 Sensitivity Analysis Results ............................................................................... 24

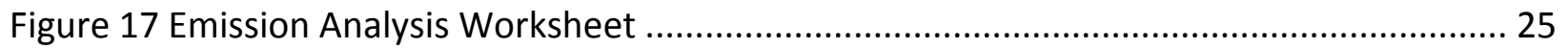

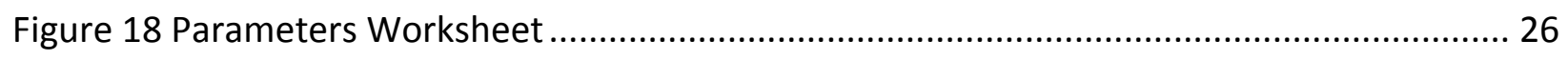

Figure 19 Accessing the Elasticity Parameters.................................................................... 35 


\section{Acknowledgments}

The authors wish to thank those individuals who tested TRIMMS 3.0 and provided useful advice on designing and implementing the new version.

FDOT Project Manager

Amy Datz

Florida Department of Transportation, Office of Public Transportation

\section{CUTR Project Team}

Principal Investigator: Sisinnio Concas, Ph.D.

Co-Principal Investigator: Philip L. Winters

Nagesh Nayak, Graduate Research Assistant

Working Group

Transportation Demand Management 


\section{Executive Summary}

Investment in public transportation can provide a cost-effective and efficient means to reduce greenhouse gas emissions (GHG). The Florida Department of Transportation (FDOT) has been actively engaged in identifying GHG reduction strategies for transit. Additionally, FDOT is working on creating a GHG baseline for each transit agency in Florida, and research efforts have focused on ozone emission reductions. When prioritizing transit capital investment strategies geared at emission reductions, focusing on ozone emissions can result in a limited evaluation of some scenarios or strategies. For example, while investments in bus rapid transit might represent a cost-effective solution due to lower capital and infrastructure costs, it might prove less efficient compared to light rail transit in terms of emission reduction attainment when the whole range of pollutants is taken into consideration. Evaluation tools that focus only on ozone reduction strategies may underestimate the relevance of other criteria pollutants. Transit services such as bus transit and bus rapid transit usually rely on diesel fuel, which produces other health-affecting pollutants, such as particulate matter (PM). Fine inhalable particles tend to have the greatest impact on health as they pass deep into the lungs, thus leading to severe respiratory diseases.

The research objective is to develop a low-cost methodology for assessing the full benefits and costs associated with the implementation of the mobile source ozone reduction strategies while accounting for a broader spectrum of emission pollutants.

\section{Results}

The research team accomplished the objective by extending the TRIMMS ${ }^{\text {TM }}$ (Trip Reduction Impacts of Mobility Management Strategies) model, developed by the National Center for Transit Research and the Center for Urban Transportation Research at the University of South Florida under a grant from the Florida Department of Transportation and the U.S. Department of Transportation.

This research resulted in a substantial upgrade to TRIMMS estimation capabilities, leading to TRIMMS 3.0. The new version now estimates a wider range of emission pollutants and incorporates a new module that evaluates the impact of land use strategies on transit patronage levels. In addition, using feedback from a pool of current users and TDM experts, TRIMMS underwent major interface and usability improvements.

TRIMMS also uses the emission inventory of the newly developed Environmental Protection Agency (EPA) Motor Vehicle Emission Simulator (MOVES2010a), which makes it suitable to run 
official State Implementation Air Quality Plan (SIP) and regional emissions analyses for transportation conformity purposes.

TRIMMS enables FDOT, transit agencies, MPOs and local communities to estimate quickly changes in emissions and the societal benefits in changes in travel behavior in a similar manner as highway cost-benefit analyses. Practitioners can conduct cost-benefit assessments for most of the strategies identified in the FDOT-sponsored Transit Ozone-Reduction Strategies Toolbox without the cost and expertise required by models that are more sophisticated.

\section{Further Research}

During the preparation of this report and the update to TRIMMS 3.0, the EPA Office of Transportation and Air Quality (OTAQ) released a report that analyzes the potential role travel efficiency strategies can play in helping reduce criteria air pollutants and GHG emissions at the national level [1]. EPA is also releasing a second report that will provide guidance to states and local government deciding to undertake similar assessments. The studies made extensive use of the TRIMMS model. As part of the findings, EPA concluded that additional research is needed to understand the impact of congestion pricing strategies in influencing travel behavior and reducing criteria air pollutants. In particular, the EPA report points to the necessity to estimate the impacts associated with land use and congestion pricing strategies. While this new version of TRIMMS includes the land use module, its capacity needs to be expanded to evaluate the impact of congestion pricing strategies affecting travel speeds. A future extension of the model would incorporate a module capable of estimating changes in average traveling speed in response to pricing strategies, as well as evaluating the benefits associated with travel time reliability changes.

Some users of TRIMMS 2.0 also requested a version that estimates the impacts of these strategies in terms of benefits to businesses. For example, they want to know what is the effect of telework and compressed workweek programs on productivity, overhead expenses, employee turnover, and absenteeism. This could be another extension to the model in the future. 


\section{Introduction}

\subsection{Introduction}

TRIMMS'M (Trip Reduction Impacts of Mobility Management Strategies) is a sketch-planning, spreadsheet-based application designed to evaluate travel demand management initiatives, which also include emission reduction strategies of transit investments focused on access and travel time improvements. TRIMMS is currently being used by several local planning agencies across the U.S., by the Washington State Department of Transportation [2], and also by the Environmental Protection Agency [1].

TRIMMS enables the user to quantify the net social benefits of a wide range of transportation demand management (TDM) initiatives in terms of emission reductions, accident reductions, congestion reductions, excess fuel consumption, and adverse global climate change impacts. This feature allows the user to conduct TDM evaluation to meet the Federal Highway Administration Congestion and Air Quality (CMAQ) Improvement Program requirements for program effectiveness assessment and benchmarking.

This final report provides guidance to help TDM professionals to use the model by selecting the appropriate cost parameters, providing referenced sources where such parameters can be obtained, and by offering general guidance on how to incorporate data already at their disposal.

\subsection{Objectives}

The objective of this research is to extend the evaluation of transit emission reduction strategies to provide a methodology for assessing the full benefits and costs associated with the implementation of ozone reduction strategies and to account for a broad spectrum of emission pollutants. The range of pollutants will include carbon dioxide $\left(\mathrm{CO}_{2}\right)$, carbon monoxide (CO), volatile organic compounds (VOCs), nitrogen oxides $\left(\mathrm{NO}_{\mathrm{x}}\right)$, sulfur oxides $\left(\mathrm{SO}_{\mathrm{x}}\right)$, and particulate matter (PM).

This objective is accomplished by extending the TRIMMS model to include a set of modules focused on evaluation of transit investment strategies. This project would result in a model to enable FDOT, transit agencies, MPOs and local communities to quickly estimate changes in emissions and the societal benefits in changes in travel behavior in a similar manner as highway cost-benefit analyses. Practitioners will be able to conduct cost-benefit analyses of the most relevant strategies identified in the FDOT-sponsored Transit Ozone-Reduction Strategies Toolbox [3] without the cost and expertise required of models that are more sophisticated. 


\subsection{Research Approach}

The research team began with the collection of all necessary input parameters required to estimate the identified GHG reduction strategies, specifically:

- Update default parameters for 99 metropolitan statistical areas to be loaded in the updated version of the model, focusing on default parameters that are specific to Florida.

- Revisit each mode demand function to incorporate additional elasticities that allow estimation of impacts from those strategies identified in FDOT's Transit OzoneReduction Strategies Toolbox.

- Update the emission parameter database using the EPA Motor Vehicle Emission Simulator (MOVES2010a).

- Develop an additional module to estimate the impact of land use strategies to promote transit use.

- Develop a technical document to guide practitioners through the use and customization of the model, and list all input parameters data sources.

\subsection{Report Organization}

Chapter 2 presents an overview of TRIMMS and describes the upgrades to Version 3.0. Chapter 3 goes into detail on the model's modules and layout. Chapter 4 details the model's parameters and provides guidance and sources on how to substitute default parameters with custom parameters. Chapter 5 specifies which strategies listed in the Transit Ozone-Reduction Strategies Toolbox TRIMMS can evaluate. Chapter 6 provides conclusions and offers direction for further research. 


\section{About TRIMMS 3.0}

\subsection{TRIMMS Development}

TRIMMS was developed by the National Center for Transit Research and the Center for Urban Transportation Research at the University of South Florida, under a grant from the Florida Department of Transportation and the U.S. Department of Transportation [4, 5]. TRIMMS is a Visual Basic (VB) application and spreadsheet model that estimates the impacts of a broad range of transportation demand initiatives and assesses program cost effectiveness, such as net program benefit and benefit-to-cost ratio analysis.

TRIMMS evaluates strategies directly affecting the cost of travel, like employer-based subsidies to promote public transportation use, parking pricing, pay-as-you-go pricing, and other financial incentives. Employer-provided subsidies reduce the costs associated with the use of a particular method of commuting to employees. Subsidies can take different forms such as cash, discount passes, and vouchers.

TRIMMS also evaluates the impact of strategies affecting access and travel times and a host of employer-based program support strategies, such as TDM program support initiatives, alternative work schedules, telework and flexible work hours, and worksite amenities.

TDM program support includes rideshare matching services, the provision of guaranteed ride home or emergency ride home for vanpool and carpool users; vanpool formation support; program promotion; and employee transportation coordinators. Alternative work schedules include compressed workweek, flexible working hours, and telework. Worksite amenities include the provision of childcare facilities and the presence of sidewalks connecting transit stops within or near the worksite.

Figure 1 shows the model structure. TRIMMS predicts mode share and vehicle miles of travel (VMT) changes brought about by the above TDM initiatives using constant elasticity of substitution (CES) trip demand functions. These functions estimate changes from baseline trip demands taking into account travelers' responsiveness to changes in pricing and travel times. The evaluation of program support strategies is based on regression equation coefficients that weight the relative strength of program support strategies and pricing strategies. Appendix A1 details the modeling technique and the use of these demand functions. 


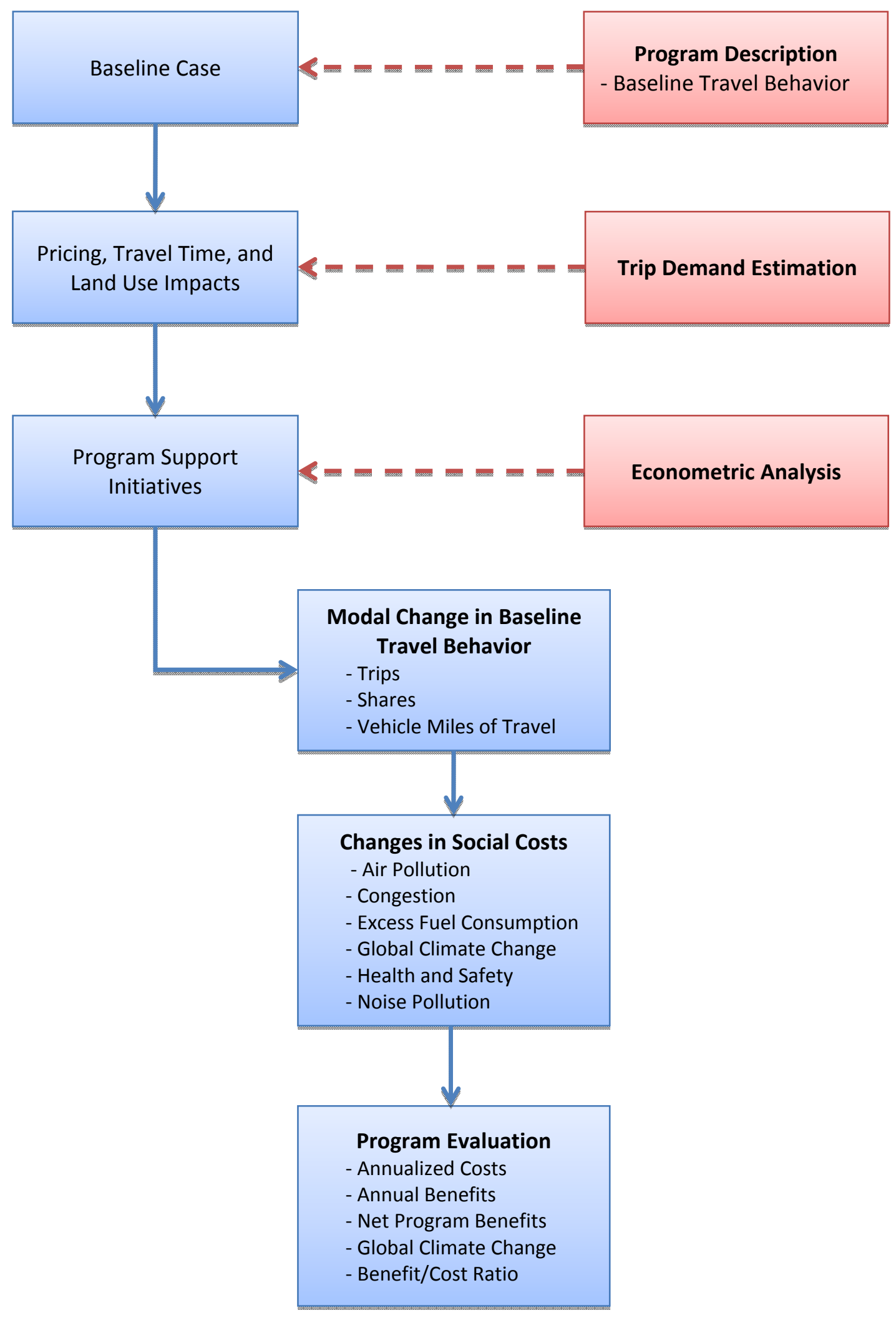

Figure 1. TRIMMS Model 
Starting from a baseline scenario describing a TDM program in terms of commuter travel behavior (mode shares, average trip lengths, peak and off-peak spreads), TRIMMS evaluates the impacts of TDM implementation by estimating changes in travel behavior (mode shares, VMT reductions). The model uses changes in the baseline scenario to estimate changes in the external costs associated with these travel behavior changes.

Generally, costs that directly affect transportation users are defined as internal costs and those costs that do not directly affect these users are defined as external costs. External or societal costs belong to what economists describe as negative externalities. Negative externalities arise whenever costs associated with single occupant vehicle (SOV) use, such as added congestion delay, air pollution, and increased accident risk, are not directly incurred by auto users but are rather imposed on the society as a whole. TRIMMS estimates changes in costs for the following externalities:

- Air pollution emissions

- Added congestion

- Excess fuel consumption

- Global climate change

- Health and safety

- Noise pollution

\subsection{New or Updated Features of Version 3.0}

In response to TRIMMS Version 2.0 users' comments, TRIMMS presents significant upgrades, including a new interface, updated default parameters for 99 U.S. metropolitan statistical areas (MSAs), a wider range of emission pollutants, and a new module that allows estimating the impact of land use controls on transit patronage levels.

\subsubsection{New Interface}

The new interface reduces the number of steps required to conduct the analysis, customize the data and update the analysis results. The upgrade relies on Microsoft Office ribbon interface (Figure 2). Upon starting TRIMMS, a custom toolbar in loaded into Excel Ribbon. The ribbon interface eliminates the need to use icon-based buttons in the worksheets, a feature of the previous version. 


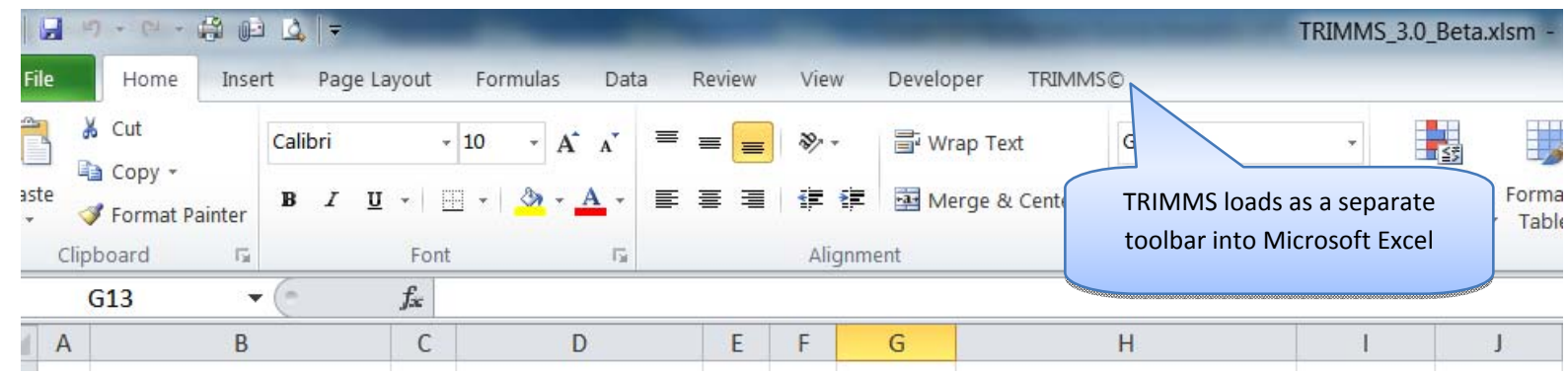

Figure 2. TRIMMS and Microsoft Excel Ribbon Toolbar

\subsubsection{Comprehensive Emission Analysis}

TRIMMS now evaluates the impact of a wider range of air pollution emissions. It uses default emission data from the EPA Agency Motor Vehicle Emission Simulator (MOVES2010a) [3]. MOVES 2010a replaced the previous emissions model, MOBILE 6.2 and can be used to conduct emission analysis to meet transportation planning and conformity requirements [4]. TRIMMS is loaded with default exhaust tailpipe emission rates for each of the 99 U.S. MSAs at the combined county level. The estimates come from the MOVES2010a inventory at the combined county level for weekday peak and off-peak periods. TRIMMS evaluates the following air pollution emissions: ${ }^{1}$

- Ammonia $\left(\mathrm{NH}_{3}\right)$

- Atmospheric Carbon Dioxide $\left(\mathrm{CO}_{2}\right)$

- Carbon Monoxide (CO)

- $\mathrm{CO}_{2}$ Equivalent

- Methane $\left(\mathrm{CH}_{4}\right)$

- Nitrogen Dioxide $\left(\mathrm{NO}_{2}\right)$

- Nitrogen Oxide (NO)

- Nitrous Oxide $\left(\mathrm{N}_{2} \mathrm{O}\right)$

- Oxides of Nitrogen $\left(\mathrm{NO}_{\mathrm{x}}\right)$

- Particulate Matter (PM10) Sulfate Particulate

- PM2.5 Total

- Sulfur Dioxide $\left(\mathrm{SO}_{2}\right)$

- Total Gaseous Hydrocarbons (HC)

- Volatile Organic Compounds (VOCs)

Note that this disaggregation also allows estimating the impact of reduction in ozone levels, as ground-level ozone exhaust emissions are produced by the chemical reaction of $\mathrm{NO}_{\mathrm{x}}$ and VOCs. Section 4.4 provides more details about the emission inventory and data customization.

\footnotetext{
${ }^{1}$ The emissions highlighted in bold represent additions in TRIMMS 3.0.
} 


\subsubsection{Land Use Impacts}

In addition to the broad range of TDM strategies discussed above, this version of TRIMMS allows estimating the impact of land use controls on transit ridership levels. These strategies include land use policy changes affecting gross population density and retail establishment density levels, transit station accessibility improvements, and transit-oriented development initiatives. The approach to estimate changes in transit demand levels is based on constantelasticity demand functions, as detailed below. Appendix A3 of the user manual provides more details about the evaluation of land use.

\subsubsection{User Manual}

This new version of TRIMMS comes with a separate user manual providing step-by-step instructions on the model's use and customization. The manual also provides detailed explanations on the model calculations, input data, and sources. The model and user manual are compressed into a single data file that can be downloaded by accessing TRIMMS's standalone website at www.trimms.com. 


\section{Using TRIMMS}

TRIMMS runs as a macro on the Microsoft Excel ${ }^{\circledR}$ software platform. Note that this version of TRIMMS only works with Microsoft Excel 2007 and 2010 versions, since it relies on the new Microsoft Office ribbon interface. TRIMMS is based on a set of macros written in Visual Basic language that allow performing the sequence of steps shown in Figure 1.

\subsection{Navigating the Toolbar}

Upon launching TRIMMS, a customized toolbar appears on the right of the Excel ribbon toolbar (Figure 3). The user can perform all relevant actions by clicking on the appropriate buttons of this toolbar. There are three main groups of buttons:

1. Analysis

2. Post Analysis

3. Model Parameters

The analysis group contains three buttons required to run the analysis. To load the default parameters and analysis options, first select the urban area (Step 1) and then select the Analysis Type option (Step 2). This step enables or disables options that apply to a site-specific or regional (area-wide) type of analysis. After entering all required information into the Analysis worksheet, click on the "Run Analysis" button to run the model (Step 3). The post analysis group contains a set of buttons to perform actions, such as printing the current screen, charting mode shares, saving the project, conducting sensitivity analysis, and resetting the model to its default values. The model parameters group contains a set of buttons to display inputs and underlying trip demand elasticities. The user manual can be accessed by pressing the appropriate button. The user manual describes each of these functions in detail.

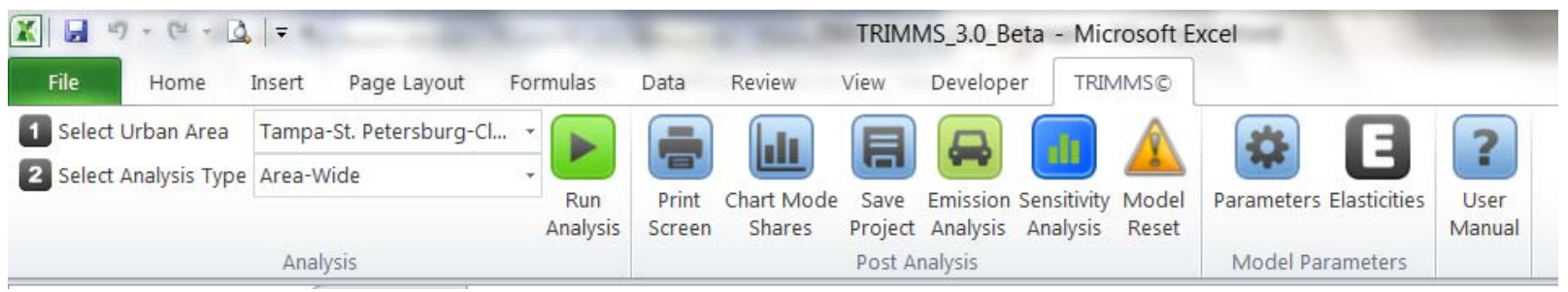

Figure 3. TRIMMS Toolbar 


\subsection{Analysis Worksheet}

After selecting the urban area and the scope of analysis, the user can enter details about the projects. These are displayed in the "Analysis" worksheet, which is automatically loaded upon launching TRIMMS (Figure 4). This is the worksheet where all the project details are stored and evaluation of all strategies can be conducted. This worksheet is divided into four main sections:

\section{Analysis Details}

2. Employer-Based Commuter Programs

3. Strategies Affecting Travel Costs and Travel Times

4. Land Use Controls

Each section displays a help icon that provides how-to suggestions for filling in information or running the analysis.

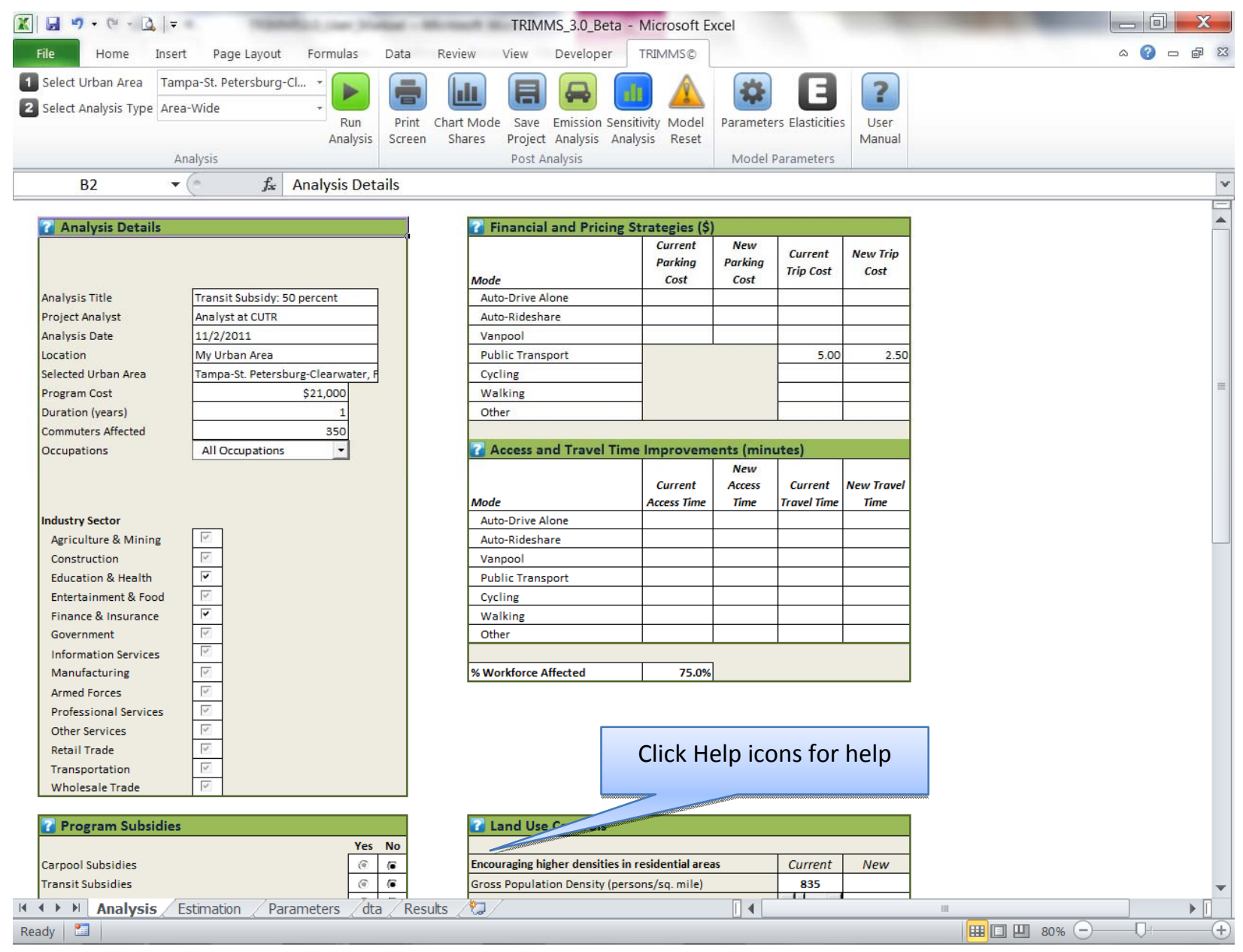

Figure 4. Analysis Worksheet 


\subsubsection{Analysis Details}

In this section, the user can enter details about the project (Figure 5). The user must enter information on program cost, duration and approximate number of employees or commuters affected by the program.

The total number of employees defines the size of the commuting population under study and is used to compute baseline vehicle trips and vehicle miles of travel (VMT). Depending on the scope of analysis, this figure can represent the size of a single employment site, the total regional employment population, or a specific target population. For example, if running an area-wide analysis, employers below a certain size might not be required to participate in trip reduction program. Therefore, the user might want to restrict the analysis to employers of a relevant size and occupational industry.

Employer support programs tend to differ in terms of magnitude based on industry sector and size. If conducting a site-based analysis, the user can only select one industry sector. This choice is mutually exclusive (i.e., no more than one sector can be selected at the same time). This tailors specific inputs, such as the prevailing wage rate used to compute congestion cost changes and the calculation of employer support programs impacts.

The user can check the industry sectors that are likely to be affected by the program if running an area-wide analysis. One or more sectors can be checked, and if the policy affects all sectors, then the user can select all of them (Figure 6). This action uses the geographic area default industry composition information from TRIMMS database file and affects the calculation of baseline mode share changes, as well as the estimation of travel time savings. Default data on sector employment levels and wage rates are displayed in the input worksheet as detailed in Section 5.2.4 of the user manual. Wages are used to compute the congestion benefits the project might produce. These change according to occupation and industry sector. To customize the wages to the analysis scope, the user needs to select the occupation type by clicking on the occupation list. This option also affects the program support evaluation as discussed in the next section. 


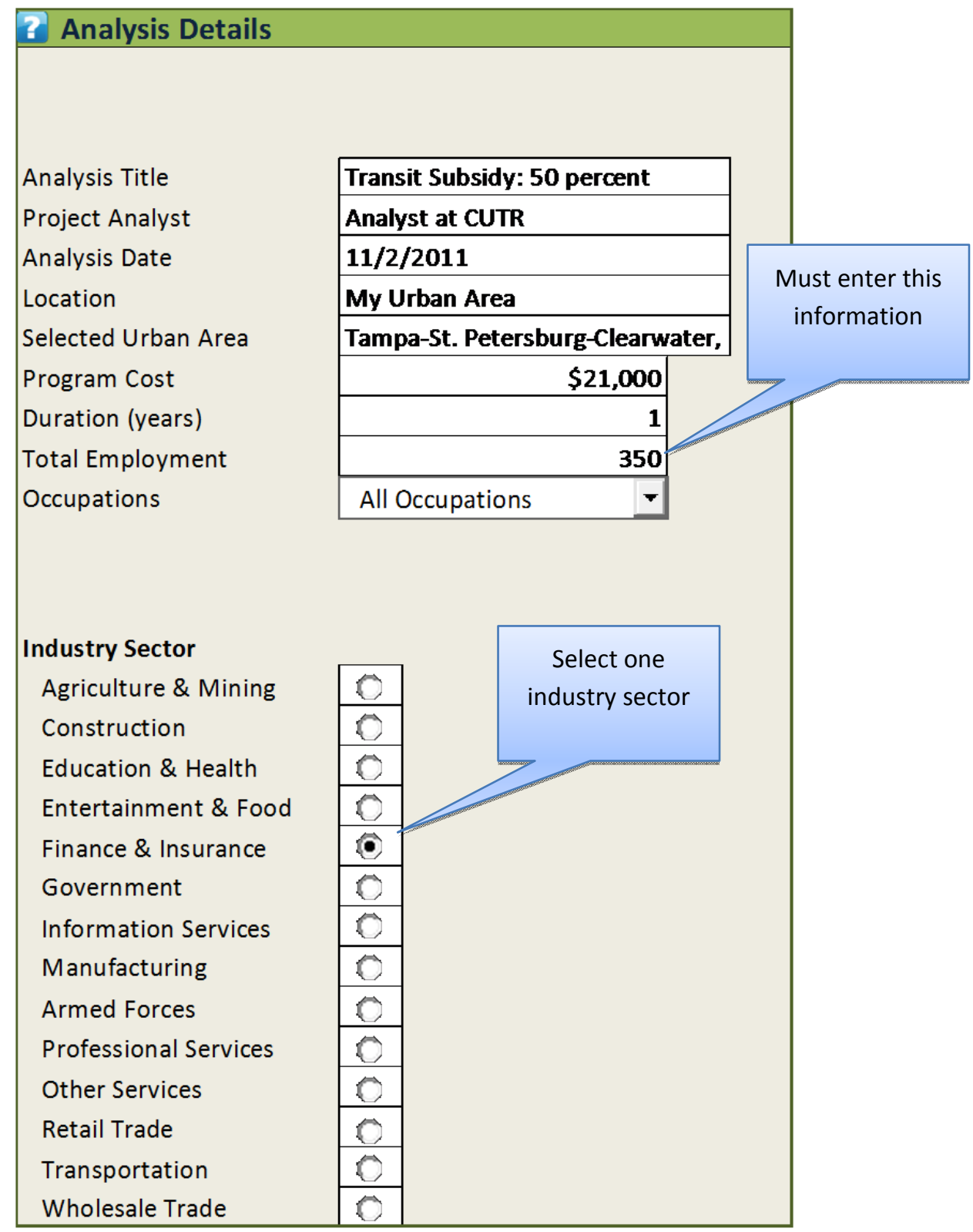

Figure 5. Site-Specific Analysis Industry Sector Options 


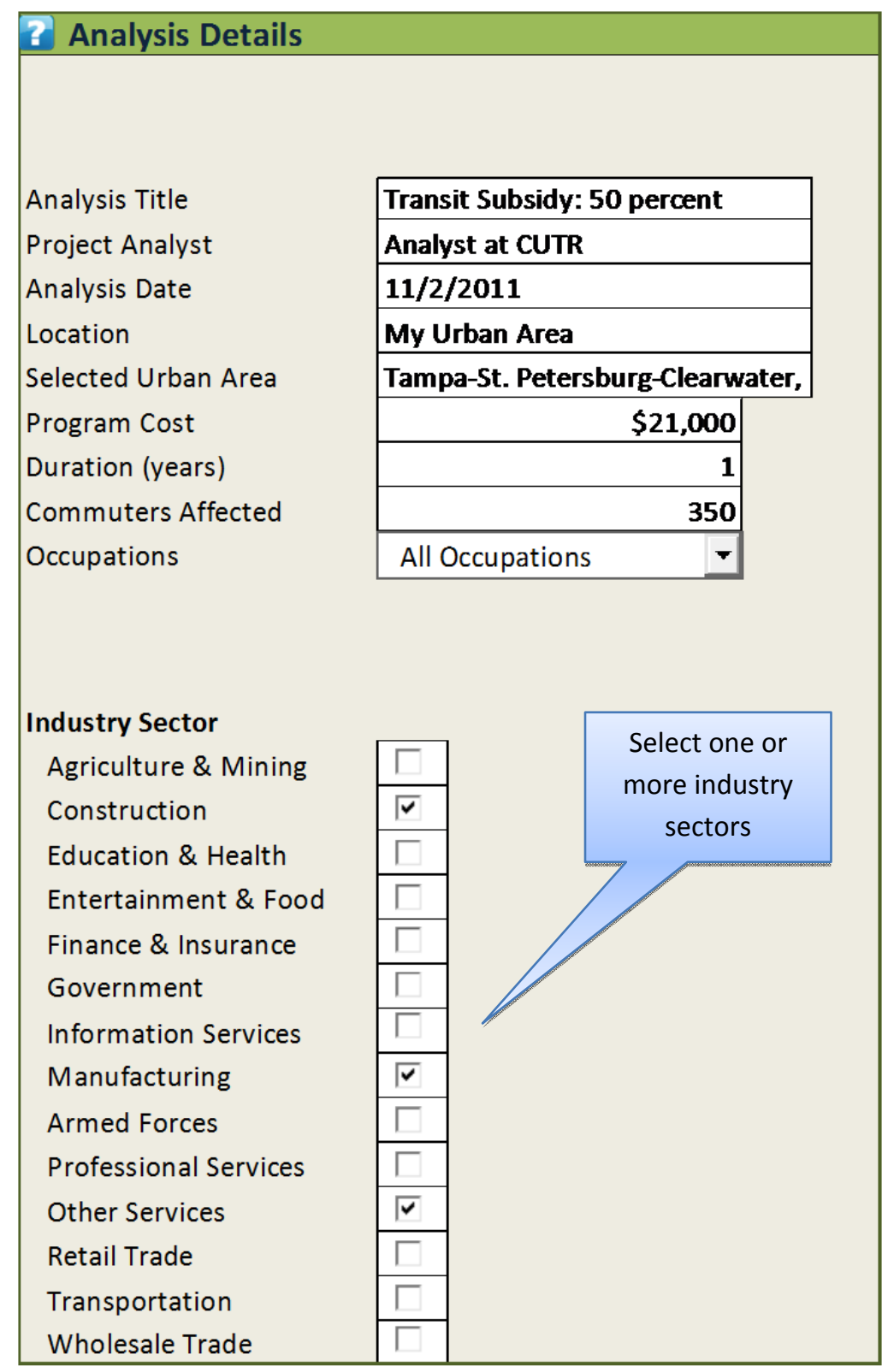

Figure 6. Area-Wide Analysis Industry Sector Options

\subsubsection{Employer-Based Commuter Programs}

In this section of the Analysis worksheet, the user can select several options related to employer support programs. As part of a project evaluation, the user can estimate the impacts of one or a combination of several commute program strategies (Figure 7). For example, the user can simultaneously evaluate the impact of a telework initiative and the promotional effort that goes along with it. Selecting a given option calls specific parameters from a regression equation that predicts the mode share impacts. This action is similar to the EPA COMMUTER model mode share balancing based on relational factors [6]. The main difference is that TRIMMS does not use relational factors based on less subjective rules of thumb about the 
efficacy and intensity of TDM support programs. Rather it uses coefficients estimated from a fixed effect equation that the authors ran on a commute trip reduction program of Washington State running over the course of three years. Appendix A. 2 provides details about the statistical technique and the estimation equation.

All options are disabled the first time the user start TRIMMS and are reset if the user changes the scope of analysis. If the user selected area-wide as the scope of analysis, then the options related to worksite characteristics are not enabled. This is because the effect of program marketing strategies is based on employer-specific actions that have an impact only at the worksite level.

\begin{tabular}{|c|c|c|}
\hline \multicolumn{3}{|l|}{ P Program Subsidies } \\
\hline \multirow{6}{*}{$\begin{array}{l}\text { Carpool Subsidies } \\
\text { Transit Subsidies } \\
\text { Vanpool Subsidies } \\
\text { Bike Subsidies } \\
\text { Walk Subsidies }\end{array}$} & \multicolumn{2}{|c|}{ Yes No } \\
\hline & C & 6 \\
\hline & 0 & (0) \\
\hline & O & 6 \\
\hline & 0 & 6 \\
\hline & 0 & 0 \\
\hline \multicolumn{3}{|c|}{ Guaranteed Ride Home and Ride Match } \\
\hline \multirow{4}{*}{$\begin{array}{l}\text { Carpool matching service offered? } \\
\text { Emergency ride home provided? } \\
\text { Vehicle for non-work trips? }\end{array}$} & Yes & No \\
\hline & 0 & 6 \\
\hline & 0 & 6 \\
\hline & O & 6 \\
\hline \multicolumn{3}{|c|}{ Telework and Flexible Work Schedules } \\
\hline \multirow{4}{*}{$\begin{array}{l}\text { Flexible working hours offered? } \\
\text { Compressed work week offered? } \\
\text { Telework program offered? }\end{array}$} & Yes & No \\
\hline & 0 & 6 \\
\hline & $B$ & (6) \\
\hline & 0 & 6 \\
\hline
\end{tabular}

\begin{tabular}{|c|c|c|}
\hline Worksite Characteristics & & \\
\hline Accessibility & Yes & No \\
\hline Bus or train station onsite or within $1 / 4$ mile & $\mathbf{D}$ & Q \\
\hline Bike lanes onsite or within $1 / 4$ mile & 0 & $\mathbf{Q}$ \\
\hline Dedicated sidewalk onsite & 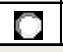 & Q \\
\hline Amenities & & \\
\hline Shopping onsite or within $1 / 4$ mile & $\mathbf{O}$ & $\mathbf{Q}$ \\
\hline Restaurant onsite or within $1 / 4$ mile & $\mathbf{Q}$ & Q \\
\hline Bank onsite or within $1 / 4$ mile & $\mathbf{D}$ & Q \\
\hline Childcare onsite or within $1 / 4$ mile & $\mathbf{D}$ & Q \\
\hline Parking & & \\
\hline Parking charge for carpooling? & $\mathbf{D}$ & $\mathbf{Q}$ \\
\hline Parking charge for vanpooling? & $\mathbf{Q}$ & $\mathbf{0}$ \\
\hline Number of free onsite parking spaces & & 150 \\
\hline Program Marketing & & \\
\hline & Yes & No \\
\hline Internal snail-mail of promotional material? & $\mathbf{D}$ & $\mathbf{Q}$ \\
\hline Internal promotional email? & $\mathbf{Q}$ & $\mathbf{Q}$ \\
\hline Do you hold promotional events & $\mathbf{D}$ & $\mathbf{Q}$ \\
\hline Program management and promotion (hrs./week) & & 8 \\
\hline
\end{tabular}

Figure 7. Employer-Based Commuter Programs Evaluation

If running an area-wide analysis, then the selection of occupation type will affect the results. This is because TRIMMS assumes that not all occupations will be equally affected by employer support programs, such as flexible working hours, telework or compressed workweek. TRIMMS default occupation levels for a given MSA reflect total occupation for each industry sector. If the user selects the "All Occupations" option, then TRIMMS will assume that employer support programs will affect all commuters. If the user selects "Administrative Support" or "Management" occupations, then TRIMMS will estimate impacts only for those occupations for the industry sector(s) the user have selected. The percent of management and administrative support occupation is reported in the "Parameter" worksheet. 


\subsubsection{Strategies Affecting Travel Costs and Travel Times}

In this section, the user can assess different TDM strategies affecting the cost of travel (Figure 8). These include the evaluation of TDM incentives directly affecting the cost of using alternative modes either by directly lowering the cost of using a mode or indirectly in the form of a subsidy. This step also allows evaluating programs or policies geared at penalizing the cost of SOV use, such as parking price changes, pay-as-you-go schemes, and other policies affecting the cost of driving. For example, to evaluate a 50 percent reduction on a transit fare for a round trip, the user must enter the current amount charged and the new amount paid after the subsidy. As part of this step, the user needs to specify the percent of workforce affected by this policy.

TRIMMS can also evaluate service improvements that target mode access and travel times. This is especially important in the evaluation of transit accessibility improvements. For example, the user can estimate public transportation access improvements that reduce the overall time it takes a worker to go to work. When evaluating an employer site, average commute times are available from employee surveys. The user can enter the survey observed commute time before the implementation of access improvements and then enters the new, expected, travel time after the improvement. TRIMMS estimates mode share changes based on these numbers so that the user can estimate the benefits associated with accessibility improvements. 


\begin{tabular}{|c|c|c|c|c|}
\hline \multicolumn{5}{|c|}{8 Financial and Pricing Strategies (\$) } \\
\hline Mode & $\begin{array}{c}\text { Current } \\
\text { Parking } \\
\text { Cost }\end{array}$ & $\begin{array}{c}\text { New } \\
\text { Parking } \\
\text { Cost }\end{array}$ & $\begin{array}{l}\text { Current } \\
\text { Trip Cost }\end{array}$ & $\begin{array}{c}\text { New Trip } \\
\text { Cost }\end{array}$ \\
\hline \multicolumn{5}{|l|}{ Auto-Drive Alone } \\
\hline \multicolumn{5}{|l|}{ Auto-Rideshare } \\
\hline \multicolumn{5}{|l|}{ Vanpool } \\
\hline Public Transport & \multirow{4}{*}{\multicolumn{2}{|c|}{$\begin{array}{l}\text { Enter current } \\
\text { and new } \\
\text { fare/trip costs }\end{array}$}} & 5.00 & 2.50 \\
\hline Cycling & & & & \\
\hline Walking & & & & \\
\hline Other & & & & \\
\hline \multicolumn{5}{|c|}{2 Access and Travel Time Improvements (minutes) } \\
\hline Mode & \begin{tabular}{c|} 
Current \\
Access \\
Time \\
\end{tabular} & $\begin{array}{c}\text { New } \\
\text { Access } \\
\text { Time }\end{array}$ & $\begin{array}{c}\text { Current } \\
\text { Travel } \\
\text { Time }\end{array}$ & $\begin{array}{c}\text { New Travel } \\
\text { Time } \\
\end{array}$ \\
\hline \multicolumn{5}{|l|}{ Auto-Drive Alone } \\
\hline \multicolumn{5}{|l|}{ Auto-Rideshare } \\
\hline \multicolumn{5}{|l|}{ Vanpool } \\
\hline Public Transport & \multirow{3}{*}{$\begin{array}{l}\text { Enter current } \\
\text { and new trip } \\
\text { travel times. }\end{array}$} & & 15.00 & 10.00 \\
\hline Cycling & & & & \\
\hline Walking & & & & \\
\hline \multirow[t]{2}{*}{ Other } & & & & \\
\hline & & & \multicolumn{2}{|c|}{ Specify percent affected } \\
\hline \% Workforce Affected & $75.0 \%$ & & & \\
\hline
\end{tabular}

Figure 8. Strategies Affecting Travel Costs and Travel Times

\subsubsection{Land Use Controls}

This section is only enabled for area-wide program evaluation (Figure 9). This is because TRIMMS assumes that land use programs or policies do not affect a specific employer worksite, but a broader area where commuters reside or work. The user can evaluate the impact of different land use policies on the demand for transit services. Upon selecting a specific urban area, default gross population and retail establishment density levels are loaded, as well as the average distance. The user can alter the parameters to simulate increases in density and accessibility levels by moving the slide bars. Note that accessibility is measured in distance to the nearest transit station. Also, another radio button allows evaluating the impact of implementing a transit-oriented development (TOD) transit station. ${ }^{2}$ The user can also specify the percent of workforce affected by these strategies. Estimation of the impacts on transit

\footnotetext{
${ }^{2}$ A TOD station is characterized by land development policies geared at facilitating transit use by improving transit station accessibility (by reducing physical barriers), and by promoting mixed land use development (residential and commercial) in their immediate surroundings.
} 
patronage from land use controls is based on a set of land use elasticity parameters produced by a simultaneous equation model of transit travel demand and urban form developed by Concas and DeSalvo [7], and summarized in a working paper in Appendix A.3 of the user manual.

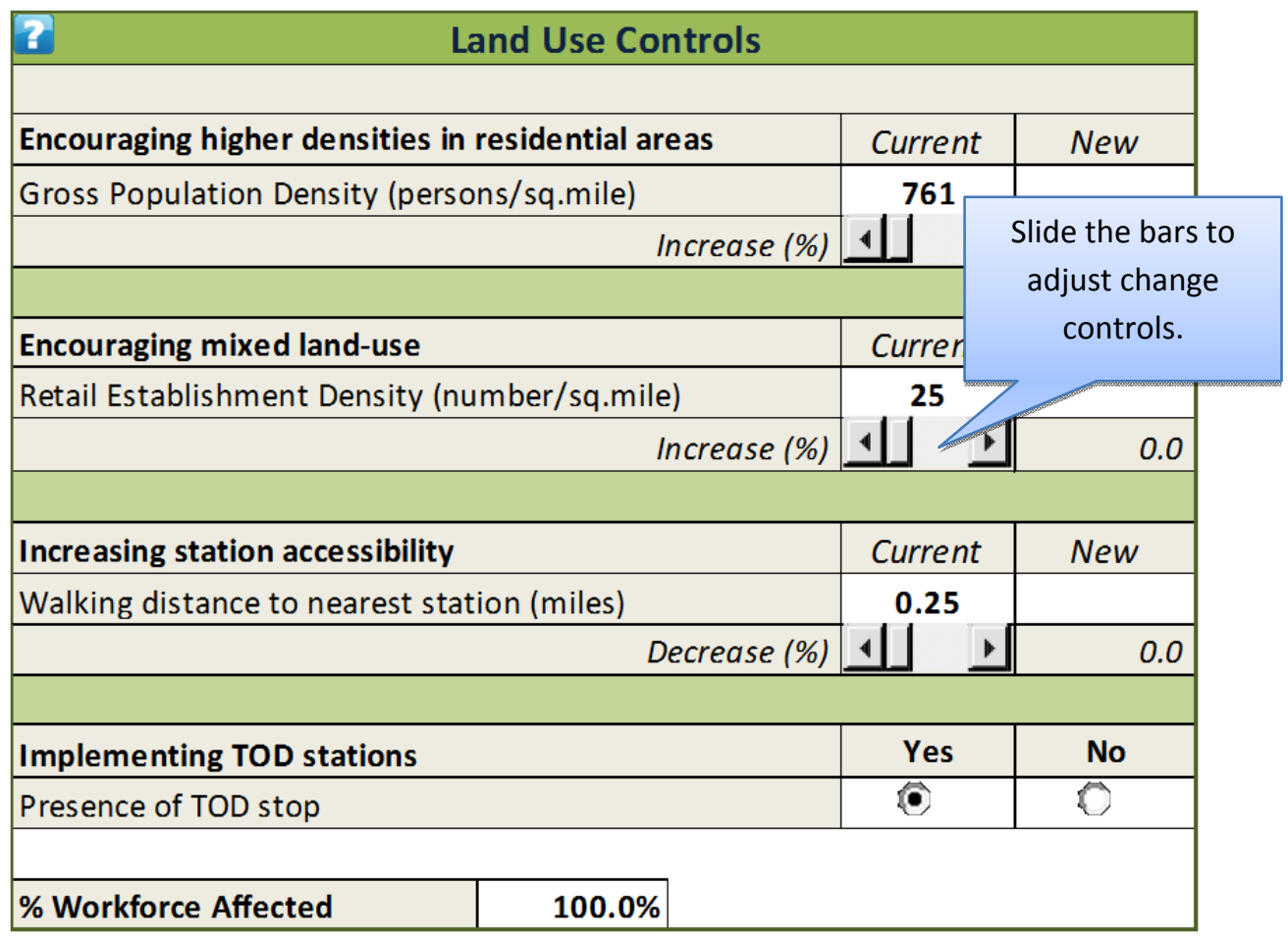

Figure 9. Land Use Controls Evaluation

\subsection{Results Worksheet}

After entering the project information, the user can run the model by clicking on the "Run Analysis" button located on the toolbar (Figure 10). TRIMMS performs all calculations and reports changes in mode share, trips, vehicle miles of travel, and changes in all relevant cost externalities. The "Results" worksheet displays a summary of output (Figure 11).

Note that if the user does not customize the input and elasticity parameters before running the analysis, the user is accepting TRIMMS default values. The user is encouraged to do a first run to see what TRIMMS estimates by default and then run a second analysis with customized inputs. This approach is discussed in more detail in the parameters section of the user manual. 


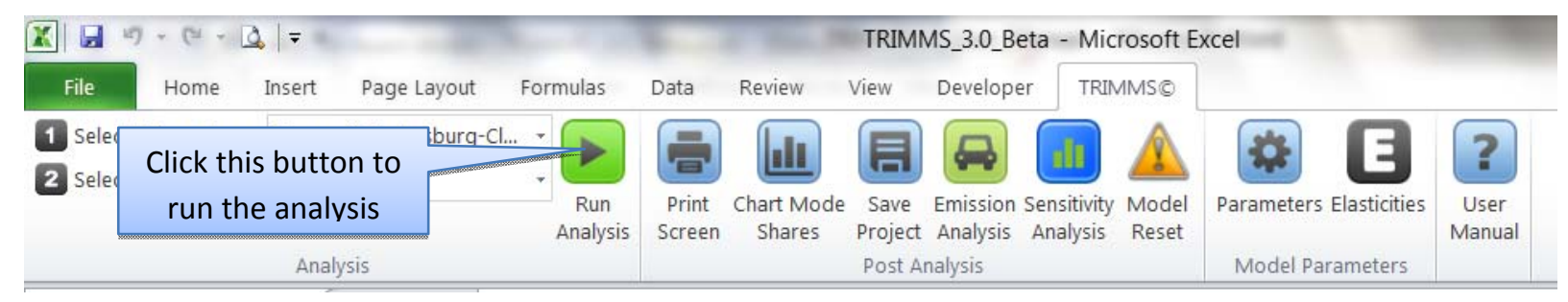

Figure 10. Running the Analysis

The user can print results, chart the changes in mode shares or save the project by clicking on the appropriate toolbar buttons. One main advantage of this upgrade is the capability of going back to the "Analysis" worksheet, changing the underlying input parameters and re-running the analysis without the need to re-enter the initial project details. For example, the user can go back to the "Analysis" worksheet and change the options the user previously selected and rerun the model. The user is encouraged to print the screen before performing this action so that the user can compare the results. This can be done by clicking on the "Print Screen" button located on the tool bar (Figure 11).

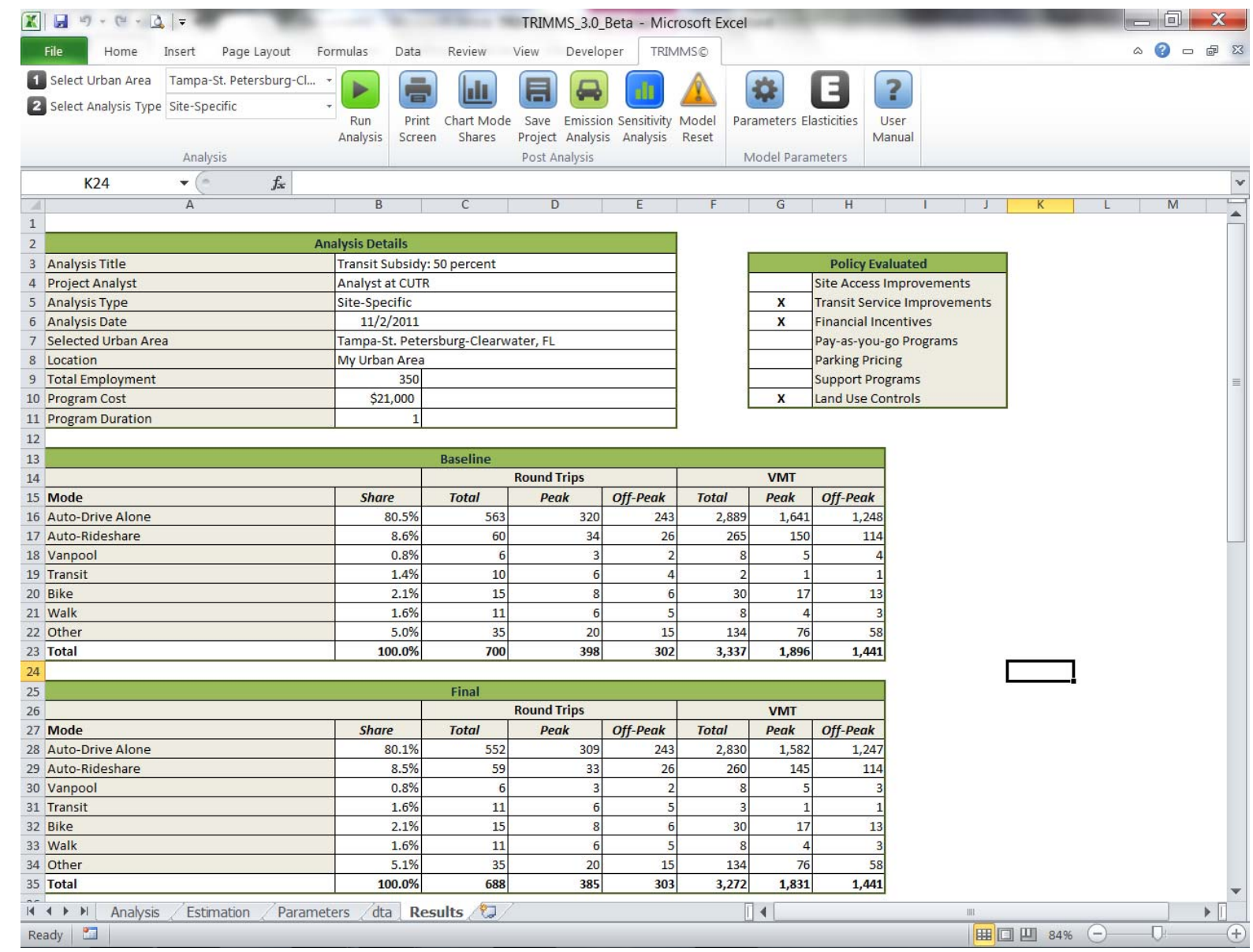

Figure 11. Worksheet Results 


\subsubsection{Baseline and Final Travel Behavior}

The Results worksheet reports all relevant results. It first displays the baseline mode shares, the number of round trips, miles of travel. Below the baseline values, it reports the estimated new mode values and then the difference between final and baseline values to gauge the project's impact on travel behavior (Figure 12).

\begin{tabular}{|c|c|c|c|c|c|c|c|}
\hline \multicolumn{8}{|c|}{ Change } \\
\hline \multirow[b]{2}{*}{ Mode } & \multirow[b]{2}{*}{ Share } & \multicolumn{3}{|c|}{ Round Trips } & \multicolumn{3}{|c|}{ VMT } \\
\hline & & Total & Peak & Off-Peak & Total & Peak & Off-Peak \\
\hline Auto-Drive Alone & $-0.33 \%$ & -11 & -8 & -3 & -58 & -42 & -16 \\
\hline Auto-Rideshare & $0.01 \%$ & -1 & -1 & 0 & -4 & -4 & 0 \\
\hline Vanpool & $0.00 \%$ & 0 & 0 & 0 & 0 & 0 & 0 \\
\hline Transit & $0.17 \%$ & 1 & 0 & 1 & 0 & 0 & 0 \\
\hline Bike & $0.03 \%$ & 0 & 0 & 0 & 0 & 0 & 0 \\
\hline Walk & $0.03 \%$ & 0 & 0 & 0 & 0 & 0 & 0 \\
\hline Other & $0.08 \%$ & 0 & 0 & 0 & 0 & 0 & 0 \\
\hline Total & $0.00 \%$ & -11 & -9 & -2 & -62 & -46 & -16 \\
\hline
\end{tabular}

Figure 12. Change in Travel Behavior (Final Estimates vs. Baseline Data)

\subsubsection{Changes in Social Costs}

TRIMMS also reports changes in social costs generated by the project and impacts on SOV travel behavior (Figure 13). Changes with a negative value correspond to a reduction in social costs and, therefore, represent a benefit. These values are reported in terms of daily dollar amounts. When annualized, the sum of these benefits produces the program total annual benefits. Finally, the Results sheet produces a benefit-to-cost ratio for program evaluation purposes. TRIMMS provides estimates of changes in external or social costs associated with:

- Air pollution

- Added congestion

- Excess fuel consumption

- Global climate change

- Health and safety

- Noise pollution

These costs are defined as external costs, or costs associated with the choice of a particular mode that are imposed to the society. For example, pollution costs, although not directly borne by a commuter, are imposed on all other individuals. These costs are used in social benefit cost analysis to compare the costs and benefits associated with a given transportation alternative. Social and external costs are also relevant to pricing and are used to compare alternative plans for efficient use of transportation systems. 


\begin{tabular}{|l|r|r|r|}
\hline Impact on Auto-Drive Alone Travel & \multicolumn{3}{|c|}{ Total } \\
\hline (a negative value is a reduction) & \multicolumn{1}{|c|}{ Peak } & \multicolumn{1}{|c|}{ Off-Peak } & -11 \\
\hline Change in Daily Round Trips & -8 & -3 & -58 \\
\hline Change in Daily VMT & -42 & -16 & -3.2 \\
\hline Change in Gasoline Consumption (gallons/day) & -2.3 & -0.9 & \multicolumn{1}{|c|}{. } \\
\hline
\end{tabular}

\begin{tabular}{|l|r|r|r|}
\hline Change in Social Costs (\$, Daily) & \multicolumn{1}{|c|}{} \\
\hline (negative value is a reduction) & \multicolumn{1}{|c|}{ Peak } & \multicolumn{1}{c|}{ Off Peak } & \multicolumn{1}{c|}{ Total } \\
\hline Air Pollution & -0.03 & -0.01 & -0.03 \\
\hline Congestion & -64.1 & -22.2 & -86.32 \\
\hline Excess Fuel Consumption & -10.1 & -3.4 & -13.58 \\
\hline Global Climate Change & -0.37 & -0.12 & -0.49 \\
\hline Health and Safety & -0.76 & -0.26 & -1.03 \\
\hline Noise Pollution & -0.51 & -0.19 & -0.70 \\
\hline Total & $-\mathbf{7 5 . 9 0}$ & $\mathbf{- 2 6 . 2 5}$ & $\mathbf{- 1 0 2 . 1 5}$ \\
\hline
\end{tabular}

Figure 13. Impact on SOV Travel and in Social Costs

\subsubsection{Changes in Air Pollution Emissions Costs}

Air pollution costs are costs associated with emissions produced by motor vehicle use. Motor vehicles produce various harmful emissions that have negative effects at local and global levels. Exhaust air emissions cause damage to human health, visibility, materials, agriculture and forests $[8,9]$. The major source of pollutants include $\mathrm{CO}, \mathrm{VOCs}, \mathrm{NO}_{\mathrm{x}}, \mathrm{SO}_{\mathrm{x}}$, and particulate matter (PM). Mobile emissions also affect global climate as gases increase the global warming effect. TRIMMS estimates changes in the costs associated with these pollutants. It also estimates changes in emissions in absolute quantities ( $\mathrm{Kg} /$ day) over the baseline case for a broader set of emission pollutants. The model reports these results separately by clicking on the "Emission Analysis" button located in the toolbar.

\subsubsection{Changes in Congestion Costs}

TRIMMS estimates the costs associated with congestion delay produced by motor vehicle use. Congestion delay is the added delay imposed to all users as an additional vehicle is introduced into the traffic stream. Any TDM initiative that removes a vehicle from the road can potentially produce benefits in terms of reductions in added delay. The cost of added delay is the opportunity cost of time spent in a motor vehicle for work or non-work related purposes; time that could be spent on other activities, such as leisure or other more work. This cost is a portion of the overall travel time costs since it only considers the portion of congestion costs generated by added delay to others. 


\subsubsection{Changes in Excess Fuel Consumption Costs}

In addition to travel time savings, added congestion contributes to excess fuel consumption. Research shows that TDM can reduce excess fuel consumption and, thus, reduce dependency from fossil fuel consumption [8, 10]. TRIMMS estimates the reduction of excess fuel consumption in total gallons per day.

\subsubsection{Changes in Global Climate Change Costs}

Climate change costs quantify the damage associated with climate change. The Intergovernmental Panel on Climate Change (IPCC) defines climate change as the "state of any change in climate over time, whether due to natural variability or as a result of human activity [11]." Trapped heat in the atmosphere is a major driver of global climate change. Gases that trap heat in the atmosphere are called greenhouse gases, such as $\mathrm{CO}_{2}$, methane $\left(\mathrm{CH}_{4}\right)$, nitrous oxide $\left(\mathrm{N}_{2} \mathrm{O}\right)$ and fluorinated gases [12]. Motor vehicle fuel production and consumption release greenhouse gases, mainly $\mathrm{CO}_{2}$, a major contributor to global climate change. EPA estimates that $\mathrm{CO}_{2}$ represents about 30 percent of all greenhouse gas emissions [13]. There are mitigation and damage costs associated with global climate change. Damage costs are costs related to the environment, health, and reduced economic productivity.

TRIMMS estimates the impact of vehicle use on climate change. It measure changes in $\mathrm{CO}_{2}$ emissions and measures the costs associated with each ton of this greenhouse gas.

\subsubsection{Changes in Health and Safety Costs}

Health and safety costs associated with crashes represent another relevant component of social costs. These include monetary costs, such as property and personal injury damages caused by collisions and cost avoidance activities, as well as nonmonetary costs, such as pain and loss of productivity. TRIMMS estimates the change in comprehensive health and safety costs associated with changes in the number of vehicle crashes of the TDM initiatives under evaluation.

\subsubsection{Changes in Noise Pollution Costs}

Noise costs quantify the damage imposed on others from motor vehicle use. Motor vehicles produce noise from engine acceleration and vibration, from tire contact on road surfaces, from break and horn usage. Noise disrupts sleep, activities, causes stress, and negatively affects property values. Several studies analyze the impact and value of external costs associated with noise emissions. TRIMMS uses default noise costs, measured in dollars per VMT, and estimates the total change in noise pollution costs resulting from a TDM and/or transit initiative. As previously described, a negative value associated with any of these cost represents a reduction 
with respect to baseline values. A reduction is equivalent to a benefit generated by the TDM and/or transit initiative under evaluation.

\subsection{Program Cost Effectiveness}

TRIMMS provides benchmarking measures in terms of annualized costs and annualized benefits, which produce a benefit-to-cost ratio.

\subsubsection{Benefit to Cost Ratio Estimation}

The sum of these daily reductions in social costs is a measure of the contribution of the TDM strategies that have been evaluated. Summed over the number of working days in a year, the model estimates the Total Annual Benefits. To obtain the Total Annualized Cost, the program total cost is annualized using a discount rate approach based on the program or project duration. The ratio of total annual benefits to total annualized cost produces the benefit-tocost $(B / C)$ ratio. The formula to compute the $B / C$ ratio is available in the user manual. The $(B / C)$ ratio can be used as a cost effectiveness benchmark. A ratio equal to 1.0 indicates that for each dollar spent on the TDM program under evaluation there is a one-dollar return in terms of social benefits. Usually, the prioritization of transportation infrastructure investments for funding appropriation relies on the $\mathrm{B} / \mathrm{C}$ ratio to produce a project-ranking list.

TRIMMS produces a summary of project net benefits and B/C ratios for peak, off-peak and a total $\mathrm{B} / \mathrm{C}$ ratio (Figure 14).

\begin{tabular}{|l|rr|rr|rr|}
\hline Program Benefits & \multicolumn{2}{|c|}{ Off Peak } & \multicolumn{2}{c|}{ Total } \\
\hline (a positive value is a benefit) & \multicolumn{2}{|c|}{ Peak } & \multicolumn{2}{|c|}{ Off } \\
\hline Total Annual Benefits (B) & $\$$ & 49,811 & $\$$ & $(21,128)$ & $\$$ & 28,683 \\
\hline Total Annualized Cost (C) & $\$$ & 25,100 & $\$$ & 25,100 & $\$$ & 25,100 \\
\hline Net Benefit (B-C) & $\$$ & 24,711 & $\$$ & $(46,228)$ & $\$$ & 3,583 \\
\hline Benefit to Cost Ratio (B/C) & & 2.0 & & 0.8 & 1.1 \\
\hline
\end{tabular}

Figure 14. Net Program Benefits and Benefit-to-Cost Ratio

\subsubsection{Sensitivity Analysis}

Another feature of TRIMMS is the implementation of a Monte Carlo (MC) simulation module. Normally, all sketch-planning tools perform a series of calculations based on a set of inputs to provide estimates of parameters of interest. Results are provided in terms of single point estimates and there is generally no way to corroborate the robustness of these results. To compensate for this shortcoming, some models provide low and high point estimates [14]. A less subjective but technically challenging way to validate results is to conduct a sensitivity analysis using MC simulation methods. These methods are useful for modeling events with 
significant uncertainty in the values of inputs. This is especially true in the case of TDM evaluation, where there is much uncertainty regarding the potential impact of TDM in terms of mode share changes and the resulting benefits. This is also relevant when modeling the changes in cost externalities, given that per unit-cost estimates vary dramatically across studies (like the cost of global warming).

In TRIMMS, the MC simulation module is set up to treat all social costs as random variables, while retaining the total annualized cost as deterministic (not subject to variation). Given the $\mathrm{B} / \mathrm{C}$ formula, the resulting $\mathrm{B} / \mathrm{C}$ ratio is itself a random variable. Through $\mathrm{MC}$ simulation, TRIMMS estimates its mean and the minimum and maximum values, defined as the $5^{\text {th }}$ and $95^{\text {th }}$ lower and upper boundary values of its distribution. These values give us an idea of how likely the single point estimates provided in the "Results" worksheet are to occur if the user were to implement the project over and over again. Another question that MC simulation can help answer is: "What is the probability that the $B / C$ ratio will at least be greater than a certain value?" Often, transportation analysts are interested in knowing if the B/C cost ratio will be greater than at least 1.0 to guarantee some returns over each dollar invested in the program.

Suppose the user ran an analysis and obtained the $\mathrm{B} / \mathrm{C}$ ratio in Figure 14 . The user might want to test: 1 ) how likely are these numbers to vary due to input cost parameter variation, and 2) what is the probability that these values will be greater than 1.0 or any other threshold value.

To answer this question the user can run a simulation by clicking on the "Sensitivity Analysis" button located on the toolbar (Figure 15).

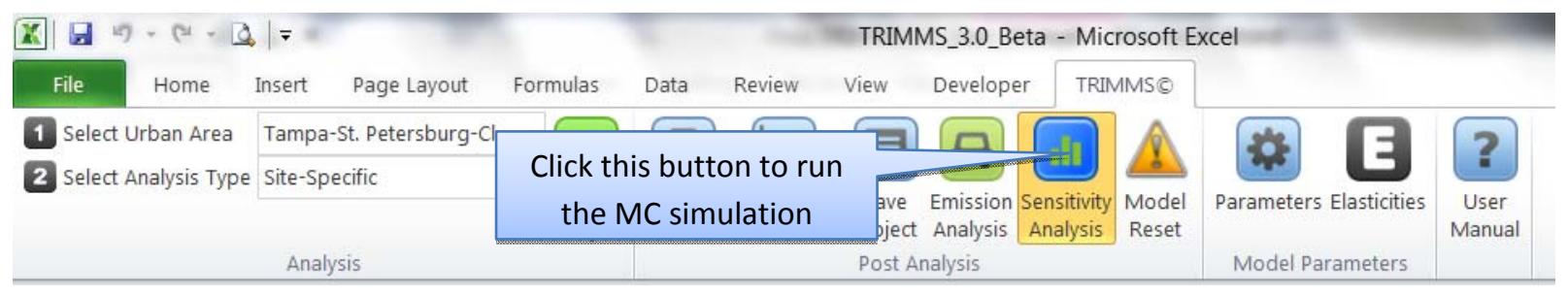

Figure 15. Sensitivity Analysis Button

By default, TRIMMS runs 7,000 iterations. On a typical personal computer (3.0 gigahertz processor and 2.0 gigabytes of random access memory) the simulation takes about one minute. Also, the default target $B / C$ ratio is set at 1.0. To run the simulation faster and customize the target B/C ratio, the user can click on the "Model Parameters" button and scroll down to the "Global Parameters" section. Please note that selecting less than 3,000 iterations does not guarantee statistical robustness of the results. Upon clicking on the "Sensitivity Analysis" button, the user starts the MC simulation. A progress status bar located on the bottom left side of TRIMMS shows percent completion information. 
Once the simulation is complete, TRIMMS displays two charts, along with the associated probabilities (Figure 16). The charts display the simulated B/C ratio distributions, the distribution mean and the minimum ( $5^{\text {th }}$ percentile) and maximum ( $95^{\text {th }}$ percentile) values. Under each chart is the estimated probability that the $\mathrm{B} / \mathrm{C}$ ratio is greater than the target value.

\subsection{Emission Analysis}

TRIMMS now includes a separate worksheet that reports estimates of changes in emission pollutions. By clicking on the "Emission Analysis" button, the user can evaluate changes in emission rates for the following air pollution emissions:

- Ammonia $\left(\mathrm{NH}_{3}\right)$

- Atmospheric Carbon Dioxide $\left(\mathrm{CO}_{2}\right)$

- Carbon Dioxide Equivalent ( $\mathrm{CO}_{2}$-Equiv)

- Carbon Monoxide (CO)

- Methane $\left(\mathrm{CH}_{4}\right)$

- Nitrogen Dioxide $\left(\mathrm{NO}_{2}\right)$

- Nitrogen Oxide (NO)

- Nitrous Oxide $\left(\mathrm{N}_{2} \mathrm{O}\right)$

- Non-Methane Hydrocarbons (NMHC)

- Oxides of Nitrogen $\left(\mathrm{NO}_{\mathrm{x}}\right)$

- Particulate Matter (PM10)

- Particulate Matter (PM2.5)

- Sulfate PM10

- Sulfur Dioxide $\left(\mathrm{SO}_{2}\right)$

- Total Hydrocarbons (HC)

- Volatile Organic Compounds (VOC)

In this worksheet, the user can also customize the emission rates by entering custom values in the User Defined cells. Results showing an increase in daily emissions are highlighted in red, while reductions are highlighted in green (Figure 17). Once the user has customized the data, another click of the "Emission Analysis" button in the main toolbar returns the user to the "Analysis" worksheet. 


\section{Benefit to Cost Ratio: Peak}

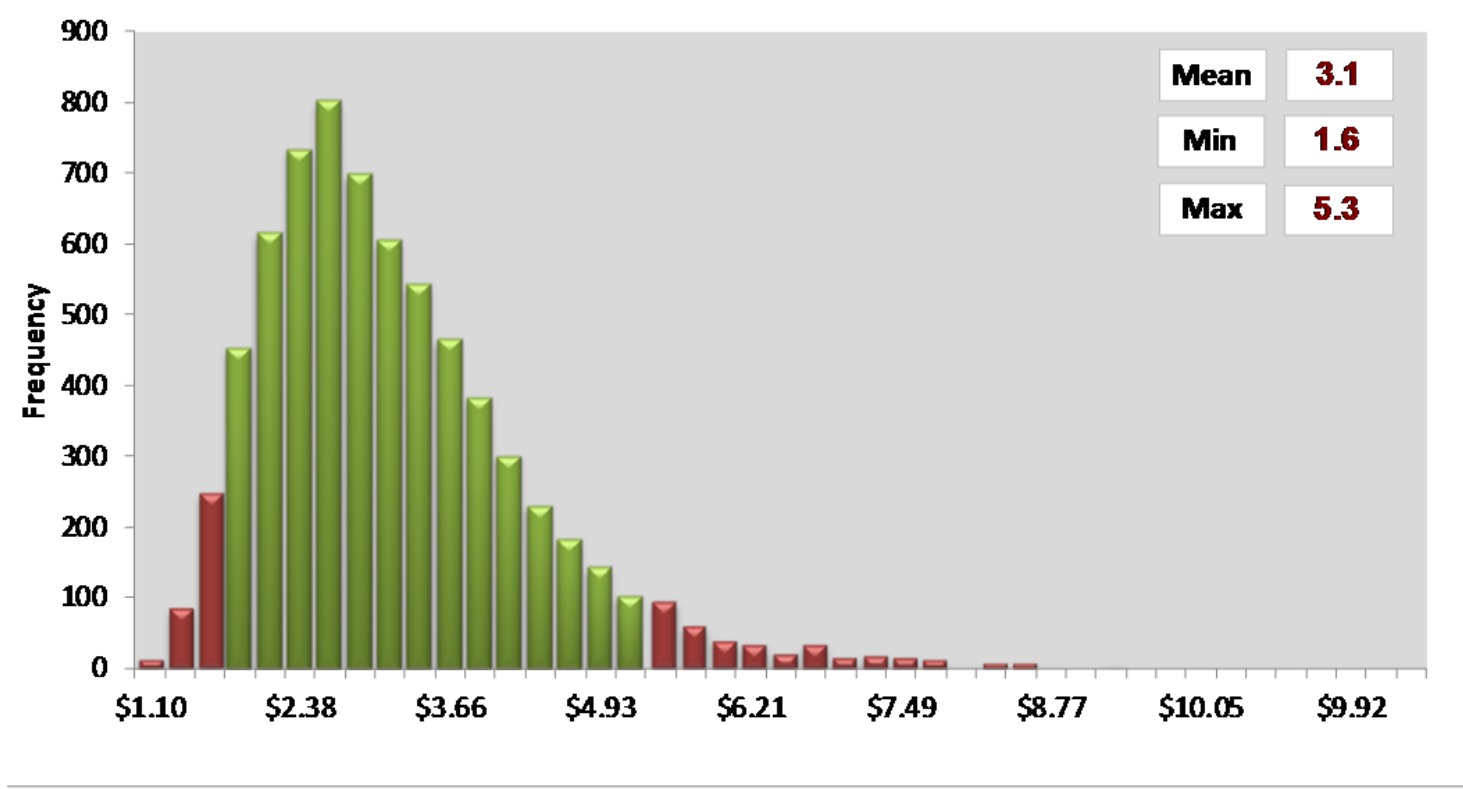

\begin{tabular}{|l|r|}
\hline Probability Benefit-to-Cost Ratio $>1$ & $99.9 \%$ \\
\hline
\end{tabular}

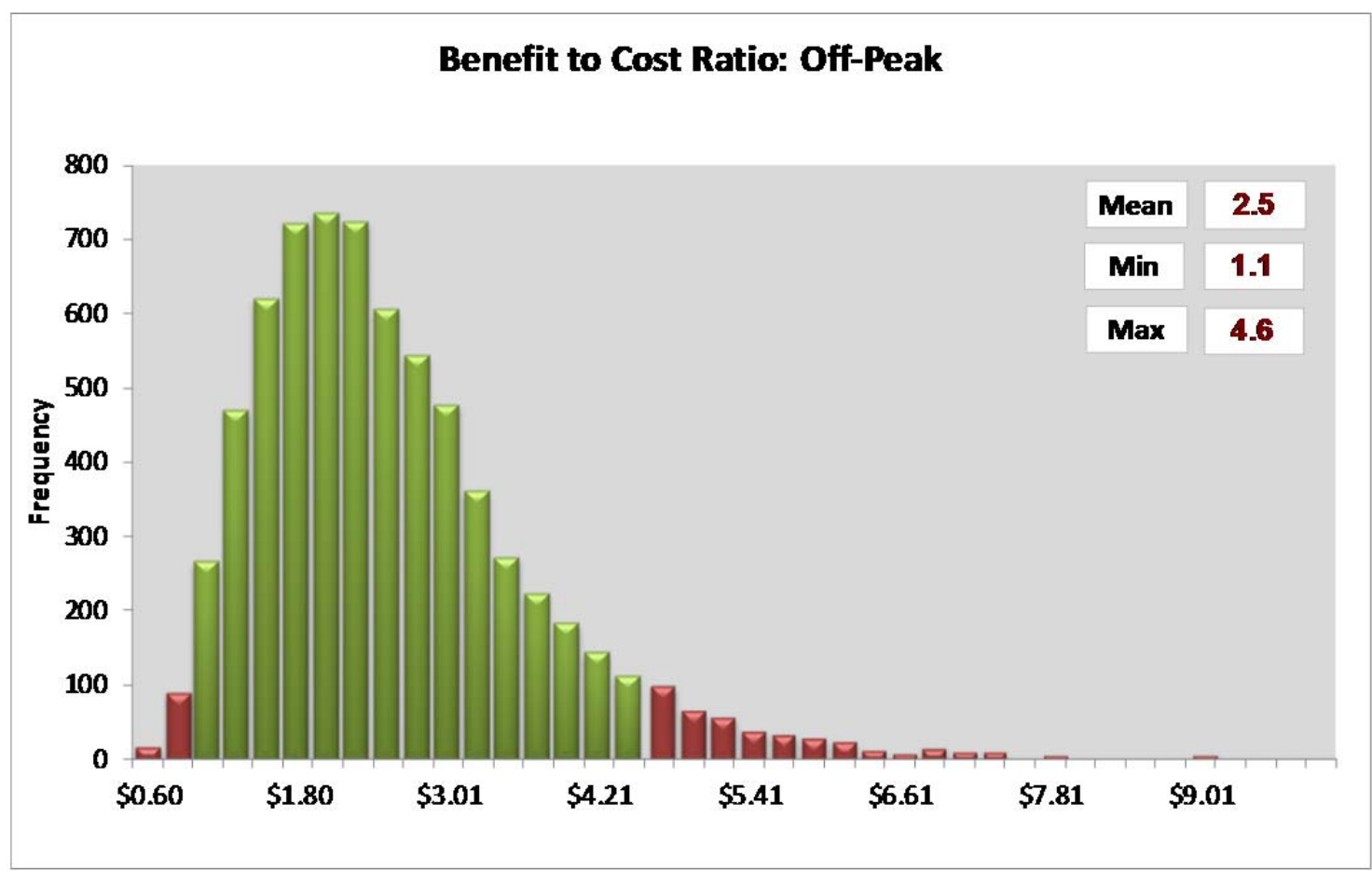

\begin{tabular}{|l|r|}
\hline Probability Benefit-to-Cost Ratio $>1$ & $96.4 \%$ \\
\hline
\end{tabular}

Figure 16. Sensitivity Analysis Results 


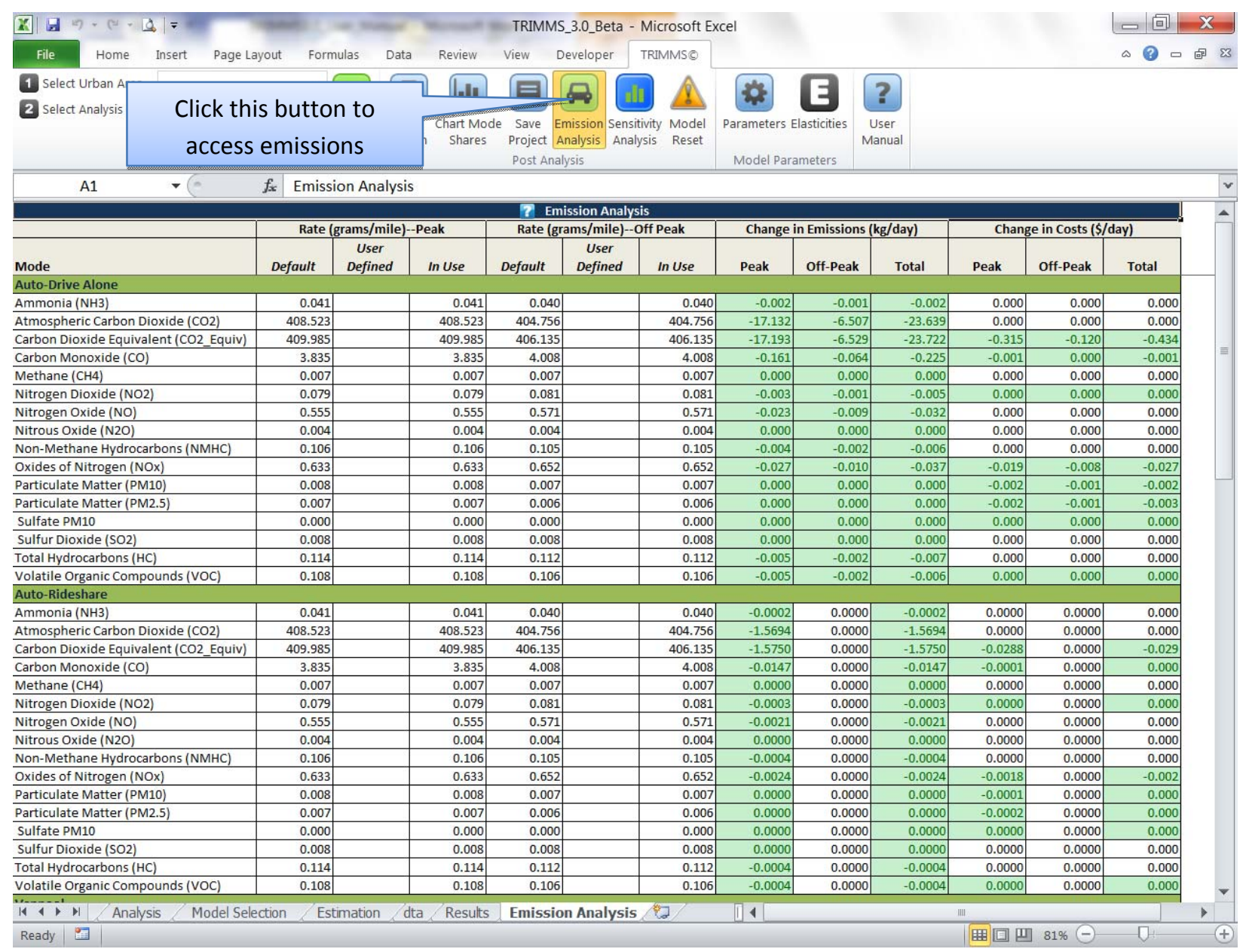

Figure 17. Emission Analysis Worksheet 


\section{TRIMMS Default Data}

As in the previous version, TRIMMS provides default values for major U.S. urban areas. Version 3.0 now includes default parameters for 99 U.S. metropolitan statistical areas (MSAs). These MSAs are representative of small, medium, large and very large urban areas.

TRIMMS uses global and regional parameters. Global parameters are default values that do not change by MSA, while regional parameters are values that are specific to a given area. The user can access and modify global and regional default input parameters by clicking on the "Parameters" button located in the toolbar, which displays the "Parameters" worksheet (Figure 18). Pressing the button again hides the worksheet and takes the user back to the "Analysis" worksheet. The following sections briefly define each of the input parameters and discuss the derivation of social costs for benefit-cost analysis. Full details on data sources, assumptions, and calculations are provided in the separate user manual.

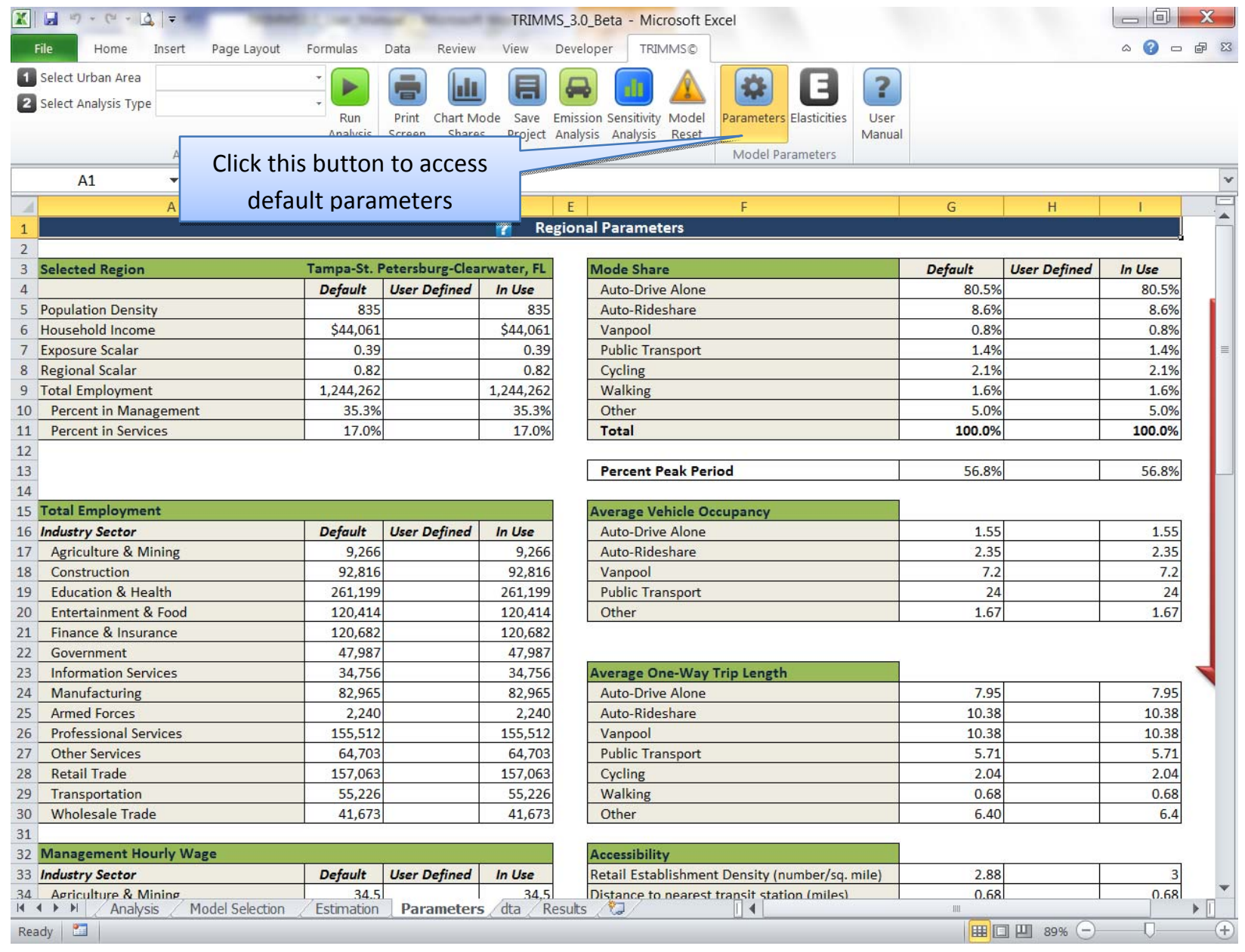

Figure 18. Parameters Worksheet 


\subsection{Global Parameters}

The following parameters are defined as global input parameters:

- Number of working days

- Household income and population density - U.S. average

- Consumer Price Index

- Discount rate

- Marginal added delay

- Fuel prices

- Fuel efficiency

- Sensitivity analysis parameters

- Social costs

\subsubsection{Number of Working Days}

By default, TRIMMS assumes there are 235 working days in year. This implies that there are 10 days of holidays, 10 days of vacation, and 5 days of sick leave. Multiplying daily benefits by the number of working days yields the total annual benefits.

\subsubsection{U.S. Median Household Income and Population Density}

TRIMMS uses the ratio of regional median household income to median U.S. household income to obtain a regional scalar that accounts for differences in the cost living of between the 99 MSAs and the U.S. The regional scalar is then applied to the original estimates of various input costs whose values represent national averages to customize them to the selected MSA. The median household income comes from the 2005-2009 American Community Survey (ACS) [15].

To adjust the exposure to emission pollutants, TRIMMS scales the emission parameters using the ratio of MSA population density to the U.S average. The average population density comes from the U.S. Census Bureau.

\subsubsection{Consumer Price Index}

The Results sheet provides estimates of costs and benefits in current dollars. Since many of the inputs are culled from many sources and analyses conducted in different years, they must be adjusted from their original values. TRIMMS uses the Consumer Price Index (CPI) to translate all input costs in current dollars. For example, the U.S. median household income is reported in 2009 inflation-adjusted dollars. TRIMMS uses the not-seasonally adjusted CPI for all urban consumers from the Bureau of Labor Statistics [16]. To allow running the analysis for future years, the model is loaded with CPI values for the years 2011-2020 assuming a 2.5 percent annual growth rate over the $2011 \mathrm{CPI}$ base. 


\subsubsection{Discount Rate}

TRIMMS uses the discount rate to convert the total program cost into an annualized cost by discounting it into constant-dollar flows. The default discount rate is 0.4 percent, which is equal to the 5-year real discount rate published by the Office of Management and Budget of the White House and used for cost-effectiveness analysis [17].

\subsubsection{Marginal Added Delay}

Marginal added delay results from the presence of one extra vehicle on the road and is measured in added hours of delay per thousands of passenger-car equivalent (pce) VMT. TRIMMS employs a default value of 61.26 hours of delay per 1,000 pce VMT, as reported by Sinha and Labi [18] who referred to the Highway Economic System Requirements technical documentation [19]. The marginal added delay is used to compute changes in added congestion to others. This is explained in detail in the social cost section of this manual.

\subsubsection{Fuel Prices and Fuel Economy}

TRIMMS uses the annual average cost per gallon of fuel net of taxes provided by the Energy Information Administration [20]. The estimate does not include taxes since they are a transfer from consumers to government or producers and do not represent an economic social cost. Note that while TRIMMS uses national averages, fuel costs are also adjusted using the regional scalar (ratio of MSA to U.S. median income). Fuel economy data for passenger cars and public transit come from the Bureau of Transportation Statistics [21]. Fuel price and fuel economy values are used to estimate the cost of excess fuel consumption.

\subsubsection{Sensitivity Analysis Parameters}

These are parameters needed to run the $M C$ simulation of the $B / C$ ratio, as discussed in Section 4.3.2. The default target $B / C$ ratio is set at 1.0 . It evaluates the probability that the project will return one dollar in benefits for each dollar of spent. The number of iterations is set at 7,000 and should not be changed, unless the computer has very limited processing capabilities.

\subsubsection{Social Costs}

TRIMMS uses default values to estimate changes in external costs generated by the analysis. Unit costs were culled from the literature for each of the categories of externalities. TRIMMS uses the CPI adjustment factor to translate all unit costs into current dollars. Section 5 of the user manual provides detail on estimation and sources for each of the cost externalities. 


\subsection{Regional Parameters}

This is a set of parameters whose values are specific to the default MSAs or any other regional area defined by the project's scope. The following parameters are defined as regional input parameters:

- Baseline travel behavior data

- Population and retail establishment density

- Retail establishment density

- Household income

- Industry employment and wages

- Accident rates

\subsubsection{Baseline Travel Behavior Data}

TRIMMS uses default mode shares, trip length, and vehicle occupancy levels to establish the baseline travel behavior data. Mode share estimates come from the 2007-2009 American Community Survey (ACS), using mean values for workers 16 years and over. Average trip length and vehicle occupancy come from the 2009 National Household Travel Survey. NHTS provides estimates for 50 of the Metropolitan Statistical Areas (MSA), and also by size of MSA. TRIMMS uses national averages for those MSA where average estimates are not available.

\subsubsection{Population Density}

Population density measures the number of persons per square mile. TRIMMS provides default population density estimates for all 99 MSAs. As described in the next section, TRIMMS uses the ratio of population density to the U.S average population density to adapt the original pollution costs estimated by Delucchi [22] to the specific area under analysis. Population density estimates come from the U.S. Census Bureau Summary File 3 [23]. Population density is also used under the Land use Controls to estimate the change in transit travel resulting from policies affecting population density levels as part of an area-wide program evaluation. When customizing this input, the user should use the U.S. Census Bureau's American Fact Finder and obtain population density estimates for the specific area of interest.

Retail establishment density measures the number of retail establishments per square mile. It is used as a proxy for land use mix (commercial land uses) in the Land use Controls analysis. The number of retail establishments comes from the U.S. County Business Patterns [24].

\subsubsection{Household Income}

The ratio of regional median household income to median U.S. household income is usedto obtain a regional scalar that accounts for differences in the cost living of between each MSA 
and the U.S. Median household income estimates come from the 2007-2009 ACS (Table B19013). When customizing this input to a region other than a default MSA, the user should use U.S. Census Bureau American Fact Finder.

\subsubsection{Industry Employment and Wages}

Industry employment and wages are used to estimate changes in congestion costs. Wages are employed to estimate the value of time for commuters and employment levels are used to weigh responsiveness to employer support program strategies. TRIMMS uses the May 2010 Bureau of Labor Statistic wage estimates by occupation type [25]. Employment levels by industry are obtained from the 2007-2009 ACS.

\subsubsection{Accident Rates}

TRIMMS provides baseline accident rates to estimate health and safety benefits. Accident data come from the National Highway Traffic Safety Administration Fatality Analysis Reporting System (FARS), which reports crash rates by severity. To substitute the default crash rates with area-specific values, the user can run a query on the FARS system [26].

\subsection{Social Costs}

To estimate changes in social costs, TRIMMS follows the methodology developed for the previous TRIMMS version [5]. As described in the previous section, all of the default parameters associated with the social costs can be changed.

\subsubsection{Congestion Costs}

TRIMMS considers two congestion related external costs: the cost of added delay to others from vehicles entering into the traffic stream and the cost of excess fuel consumption due to lower average fuel economy in congested conditions.

The cost of added delay is the opportunity cost of time spent in a motor vehicle for work or non-work related purposes; time that could be spent on other activities, such as leisure or other more work. This cost is a portion of the overall travel time costs since it only considers the portion of congestion costs generated by added delay to others from vehicles entering into the traffic stream. Following findings from a recently published NCTR report on the value of time [27], TRIMMS measures the value of time for commuting purposes as 100 percent of the prevailing average wage rate.

The total cost of excess fuel consumption is equal to the total annual gallons of excess fuel consumed, multiplied by the cost of fuel, which corresponds to the annual average cost per gallon of fuel net of taxes provided by the Energy Information Administration [20]. Taxes are a 
transfer from consumers to government or producers and do not represent an economic social cost.

\subsubsection{Health and Safety}

Health and safety costs represent another relevant component of social costs. These include monetary costs, such as property and personal injury damages caused by collisions and cost avoidance activities, as well as nonmonetary costs, such as pain and loss of productivity.

TRIMMS estimates the comprehensive health and safety costs associated with vehicle crashes as the total social cost per accident by severity type multiplied by the number of crashes in each severity class; its product summed over all severity classes.

TRIMMS uses comprehensive cost estimates from the National Highway Traffic Safety Administration (NHTSA) report on the economic impact of motor vehicle crashes [28]. The report provides an estimate of average economic and comprehensive costs by maximum abbreviated injury scale (MAIS). Economic costs consist of loss of human capital, market productivity, household productivity, medical care, property damage, and travel delay. The willingness to pay to avoid these costs is included in the comprehensive cost estimates using a quality-adjustment life years (QALYs) factor loss. TRIMMS automatically scales these costs for each region using the ratio of the region's median household income to the U.S. median household income. To obtain the change in number of crashes, the estimated changes in VMT are multiplied by the accident rate of each severity class. The National Highway Traffic Safety Administration Fatality Analysis Reporting System (FARS) reports accidents in terms of number of crashes [29]. VMT estimates come from the National Highway Administration Annual Highway Statistics series [30].

\subsubsection{Air Pollution}

Air pollution costs refer to costs associated with motor vehicle use. Motor vehicles produce various harmful emissions that have negative effects at local and global levels. Exhaust air emissions cause damage to human health, visibility, materials, agriculture and forests [8, 9]. Mobile emissions also affect global climate as gases increase the global warming effect. We discuss this issue in the next section. Pollution costs are the product of three values:

- emission estimates, measured in kilogram $(\mathrm{kg}) / \mathrm{mile}$

- emission costs, measured in $\$ / \mathrm{kg}$

- vehicle miles of travel (VMT), estimated by TRIMMS

These values are summed across all vehicle classes, pollutants, and impact categories to produce estimates of total pollution benefits of each TDM strategy being evaluated. 
Default emission rates come from the EPA's latest version of MOVES (Motor Vehicle Emission Simulator), which substituted the previous vehicle emission factor model MOBILE6.2 [31]. Estimates were obtained from a batch-run of MOVES2010a for each metropolitan statistical area, using the national county-level emission inventory and estimates for weekday travel under peak and off-peak periods. Emission rates for each MSA represent a weighted average of emissions at a county level, after accepting the MOVES procedure to weigh the different vehicle stock, travel, and ambient conditions specific to each county.

If the user is using TRIMMS to obtain emission estimates to be used to conduct a transportation policy evaluation to meet transportation conformity regulations customizing the TRIMMS emission factors following the policy guidance procedure recommended by EPA [32] is strongly recommended. Alternatively, users can contact TRIMMS developers to inquire about a custom version of TRIMMS for their project. One of the major advantages of MOVES over MOBILE 6.2 is the wider range of air pollutants that can be modeled and the level of customization that can be achieved to model a specific area. MOVES also provides estimates of global warming emissions (discussed next) in terms of $\mathrm{CO}_{2}$ equivalent estimates. TRIMMS comes loaded with rates for the following air pollution emissions:

- Ammonia $\left(\mathrm{NH}_{3}\right)$

- Atmospheric Carbon Dioxide $\left(\mathrm{CO}_{2}\right)$

- Carbon Dioxide Equivalent ( $\mathrm{CO}_{2}$-Equiv)

- Carbon Monoxide (CO)

- Methane $\left(\mathrm{CH}_{4}\right)$

- Nitrogen Dioxide $\left(\mathrm{NO}_{2}\right)$

- Nitrogen Oxide (NO)

- Nitrous Oxide $\left(\mathrm{N}_{2} \mathrm{O}\right)$

- Non-Methane Hydrocarbons (NMHC)

- Oxides of Nitrogen $\left(\mathrm{NO}_{\mathrm{x}}\right)$

- Particulate Matter (PM10)

- Particulate Matter (PM2.5)

- Sulfate PM10

- Sulfur Dioxide $\left(\mathrm{SO}_{2}\right)$

- Total Hydrocarbons (HC)

- Volatile Organic Compounds (VOC)

Pollution emission costs are measured in $\$ / \mathrm{Kg}$ damages related to health and visibility impacts and physical impacts on the environment. The costs estimates of Delucchi [8], who estimated costs for several impact categories for urban areas of the U.S. in 1991, were adopted. Delucchi recently updated the original values to account for changes in information about pollution and 
its effects [14]. He customizes these estimates by using regional exposure scalars to adjust the average exposure basis in U.S. urban areas to the average exposure in each of the metropolitan statistical areas. According to Delucchi, population density is the best simple measure of exposure to air pollution. The original $1991 \$ / \mathrm{Kg}$ are converted to current dollar values using the consumer price index (CPI). To account for cost of living geographical differences, these estimates are scaled to each individual region using the ratio of median household income of each area to the U.S. median household income.

\subsubsection{Global Climate Change}

The Intergovernmental Panel on Climate Change (IPCC) defines climate change as the "state of any change in climate over time, whether due to natural variability or as a result of human activity [11]." Trapped heat in the atmosphere is a major driver of global climate change. Gases that trap heat in the atmosphere are called greenhouse gases [12]. Motor vehicle fuel production and consumption release greenhouse gases, mainly $\mathrm{CO}_{2}$, a major contributor to global climate change. EPA estimates that $\mathrm{CO}_{2}$ represents about 30 percent of all greenhouse gas emissions. There are mitigation and damage costs associated with global climate change. Damage costs are costs related to the environment, health, and reduced economic productivity.

TRIMMS employs the damage costs, or the cost of a change in greenhouse gas emissions associated with motor vehicle use. The unit of measure is the marginal damage in U.S. dollars caused by a metric ton of $\mathrm{CO}_{2}$ emissions $(\$ / \mathrm{tC})$. Since cost estimates vary widely across the literature, the estimate of $\$ 50 / \mathrm{tC}$ by Tol [33] who analyzed and combined 103 estimates of marginal damage costs of carbon dioxide emissions from 28 published studies was adopted. The mean marginal damage cost that takes into account of only peer-reviewed literature (pp.2070) is used and scales to dollar per kilogram $(\$ / \mathrm{kg})$.

Note that while TRIMMS only considers the marginal damage costs associated with $\mathrm{CO}_{2}$ emissions, other authors provide more comprehensive estimates of greenhouse emission costs. For example, Delucchi [14] considers the global emission costs of pollutants other than $\mathrm{CO}_{2}$ by calculating a ratio of $\mathrm{CO}_{2}$ equivalent emissions to $\mathrm{CO}_{2}$ emissions. Since EPA $[12,13,34]$ considers these other greenhouse gases as more volatile and difficult to estimate, the EPA approach that only models $\mathrm{CO}_{2}$ global emissions is followed.

\subsubsection{Noise Pollution}

Noise costs refer to negative externalities associated with motor vehicle noise emissions. Motor vehicles produce noise from engine acceleration and vibration, from tire contact on road surfaces, from brake and horn usage. Noise disrupts sleep, activities, causes stress, and negatively affects property values. Several studies monetize traffic noise costs (see for example, Delucchi [35]). Noise cost estimates by Tod Litman [36], who comprehensively reviews 
the literature and provides estimates by mode type for urban and rural areas, were used. These estimates are reproduced in Table 2. In TRIMMS, these costs are scaled to account for cost of living differentials between national averages and each regional area.

\subsection{Elasticity Parameters}

TRIMMS estimates changes in trips using trip demand functions that rely on constant elasticity of substitution (CES) parameters that are explained in more detail in Appendix A.1. Elasticities measure user' responsiveness to changes in pricing and travel times. Elasticities are used to measure the percentage change in demand of a good caused by a one-percent change in its price or other characteristics. For example, an elasticity of -0.5 for single occupancy vehicle trips with respect to fuel costs means that each 1 percent increase in the price of fuel results in a 0.5 percent reduction in the demand for vehicle trips.

TRIMMS trip demand functions make use of direct elasticities and cross elasticities. Direct elasticities refer to the percentage change in the demand for trips of any given mode resulting from a change in its own price or other measurable characteristics. Cross elasticities refer to the percentage change in the demand for trips of any given mode caused by a change in price or other measurable characteristics of other modes. For example, an increase in parking prices causes a direct negative percent change in the demand for auto trips and causes a positive change in the demand for transit services. The use of cross elasticities recognizes a certain degree of substitution, or mode shift, between transport modes; the intensity of substitution depends on circumstances and is measured by the cross elasticities.

To obtain default parameters, the empirical literature was surveyed. There are a number of excellent surveys of the empirical literature on the demand for transportation and the role of elasticities [37-40]. TRIMMS uses parameters from these studies and other publications.

TRIMMS default elasticity parameters can be accessed by clicking on the elasticity button on the toolbar (Figure 19). 


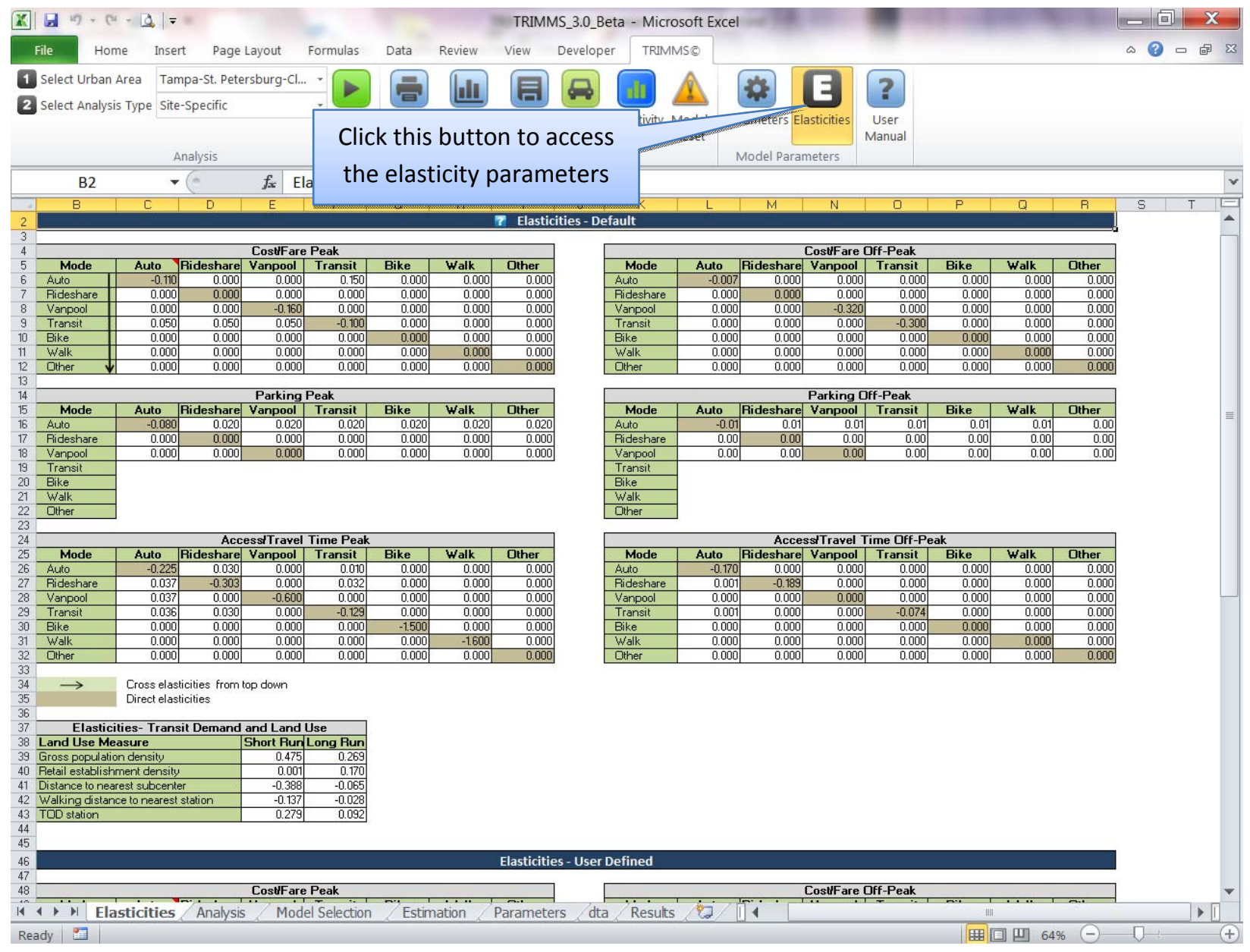

Figure 19. Accessing the Elasticity Parameters

\subsubsection{Fare and Trip Cost Elasticities}

Fare (and in general, pricing) elasticities are dynamic, as they vary over time. Researchers distinguish between short run and long run elasticity estimates. There are many definitions of short and long run, but most authors define short run to be 1 or 2 years, and the long run to be about 12 to 15 years. Since most of the TDM programs run for a period corresponding to the short run, short run estimates were adopted as default values. These estimates are on average lower than the long run, signifying that users are less responsive to price changes in the immediate future. The user can change all elasticity parameters, by clicking on the Elasticities button located in the toolbar. Table 1 reports the default values estimates for direct and cross fare and price elasticities. 
Table 1. Fare and Price Elasticities

\begin{tabular}{|c|c|c|c|c|}
\hline \multirow[t]{2}{*}{ Mode } & \multicolumn{2}{|c|}{ Elasticity } & \multirow[t]{2}{*}{ Source } & \multirow[t]{2}{*}{ Notes } \\
\hline & $\begin{array}{l}\text { short } \\
\text { run }\end{array}$ & $\begin{array}{l}\text { long } \\
\text { run }\end{array}$ & & \\
\hline \multicolumn{5}{|l|}{ Auto - Drive Alone } \\
\hline $\begin{array}{l}\text { Direct } \\
\text { Cross-Price: } \\
\text { Transit }\end{array}$ & $\begin{array}{c}-0.047 \\
0.03\end{array}$ & $\begin{array}{c}-0.241 \\
0.15\end{array}$ & $\begin{array}{l}\text { Hymel et al. [41] } \\
\text { Litman [40] }\end{array}$ & $\begin{array}{l}\text { Table 6, pp. } 1232 \\
\text { TRIMMS uses the lower } \\
\text { ranges }\end{array}$ \\
\hline \multicolumn{5}{|l|}{ Auto - Rideshare } \\
\hline $\begin{array}{l}\text { Direct } \\
\text { Cross-Price: }\end{array}$ & -0.047 & -0.241 & Hymel et al.[41] & Table 6, pp.1232 \\
\hline Transit & 0.03 & 0.15 & Litman [40] & same as auto-drive alone \\
\hline \multicolumn{5}{|l|}{ Vanpool } \\
\hline $\begin{array}{l}\text { Direct } \\
\text { Cross-Price: }\end{array}$ & -0.73 & -1.46 & Concas et al.[42] & Long run twice of short run \\
\hline $\begin{array}{c}\text { Auto } \\
\text { Rideshare }\end{array}$ & $\mathrm{n} / \mathrm{a}$ & $\mathrm{n} / \mathrm{a}$ & $\mathrm{n} / \mathrm{a}$ & $\mathrm{n} / \mathrm{a}$ \\
\hline \multicolumn{5}{|l|}{ Transit } \\
\hline Direct: Peak & -0.59 & -0.75 & $\begin{array}{l}\text { Holmgren et al. } \\
{[43]}\end{array}$ & $\begin{array}{l}\text { Table } 6 \\
\text { Our assumption: } 1.5 \text { times the }\end{array}$ \\
\hline $\begin{array}{l}\text { Direct: Off-Peak } \\
\text { Cross-Price: }\end{array}$ & -0.89 & -1.13 & Our assumption & peak \\
\hline $\begin{array}{l}\text { Auto - Drive } \\
\text { Alone }\end{array}$ & 0.05 & 0.20 & Litman [40] & Use of lower ranges \\
\hline
\end{tabular}

The transit fare elasticity estimates of Holmgren [43], who performs a meta-analysis of fare, income, level of service elasticities and vehicle ownership were adopted. These estimates are somewhat higher than the estimates of some other authors. For example, Litman [40] reports short run elasticities between -0.2 and -0.5 and between -0.6 and -0.9 for the long run.

Table 2 reports the direct and cross travel time elasticities based on estimates by Litman [40], who provides a comprehensive review of travel time elasticities. 
Table 2. Travel Time Elasticities

\begin{tabular}{|c|c|c|c|}
\hline \multirow[t]{2}{*}{ Mode } & \multicolumn{2}{|c|}{ Elasticity } & \multirow[t]{2}{*}{ Notes } \\
\hline & Peak & Off Peak & \\
\hline \multicolumn{4}{|l|}{ Auto - Drive Alone } \\
\hline Direct & -0.225 & -0.170 & \\
\hline Cross: Auto - Rideshare & 0.030 & 0.000 & \\
\hline Cross: Transit & 0.010 & 0.000 & \\
\hline \multicolumn{4}{|l|}{ Auto - Rideshare } \\
\hline Direct & -0.303 & -0.189 & \\
\hline Cross: Auto - Drive Alone & 0.037 & 0.000 & \\
\hline Cross: Transit & 0.032 & 0.000 & \\
\hline \multicolumn{4}{|l|}{ Vanpool } \\
\hline Direct & -0.303 & -0.189 & \\
\hline Cross-Price: Auto - Rideshare/Drive & & & Same as Auto: \\
\hline Alone & 0.037 & 0.000 & Rideshare \\
\hline Cross: Transit & 0.032 & 0.000 & \\
\hline \multicolumn{4}{|l|}{ Transit } \\
\hline Direct & -0.129 & -0.074 & \\
\hline Cross: Auto - Drive Alone & 0.036 & 0.000 & \\
\hline Cross: Auto - Rideshare & 0.030 & 0.000 & \\
\hline
\end{tabular}

Source: Litman [40] Table 31, pp. 35

\subsubsection{Parking Demand Elasticities}

Parking elasticity estimates are derived from a meta-analysis of elasticities culled from the literature. Results from a linear regression of 162 elasticity estimates from 25 studies produced the table below [44]. Cross price and slow mode elasticity estimates come from Litman [40] (Table 3). 
Table 3. Parking Pricing Elasticities

Parking Elasticities

\begin{tabular}{|c|c|c|c|c|}
\hline $\begin{array}{c}\text { Trip } \\
\text { Purpose }\end{array}$ & $\begin{array}{c}\text { Auto - Drive } \\
\text { Alone }\end{array}$ & $\begin{array}{c}\text { Auto - } \\
\text { Rideshare }\end{array}$ & Transit & $\begin{array}{l}\text { Slow } \\
\text { Modes }\end{array}$ \\
\hline Commuting & $-0.158 t$ & $0.02+t$ & $0.02+\dagger$ & $0.02+\dagger$ \\
\hline
\end{tabular}

\subsubsection{Land Use Control Elasticities}

TRIMMS employs CES elasticity parameters to translate change in urban form and land use variables into changes in transit ridership levels. TRIMMS assumes that an increase in transit demand is equivalent to a decrease in auto-drive demand by the same magnitude. Concas and DeSalvo [7] developed an analytical framework that models transit demand, residential location patterns, trip-chaining behavior and transit ridership levels. The comprehensive modeling framework produced a set of land use elasticities that can be used at the sketch-planning level by practitioners in the field. Short-run elasticity considers density levels and residential location and work patterns as exogenous or predetermined, while long-run estimates treat all variables as endogenous (Table 4). Based on the project duration, TRIMMS selects the proper set of parameters. Appendix A.3 in the user manual provides a synopsis of the methodology to estimate the land use elasticities. 
Estimating Costs and Benefits of Emissions Reduction Strategies for Transit by Extending the TRIMMS Model

Table 4. Land use Elasticity

\begin{tabular}{llcc}
\hline \hline \multicolumn{1}{c}{ Elasticity } & $\begin{array}{c}\text { Short } \\
\text { Run }^{a}\end{array}$ & $\begin{array}{c}\text { Medium } \\
\text { Run }^{b}\end{array}$ & Long Run $^{c}$ \\
\hline Density & 0.475 & 0.269 & $\mathrm{n} / \mathrm{a}$ \\
Walking distance to nearest station & -0.137 & -0.028 & -0.093 \\
Transit station at workplace* & 0.687 & 0.766 & 0.961 \\
TOD station* & 0.279 & 0.139 & $\mathrm{n} / \mathrm{a}$ \\
Retail establishments density & 0.001 & 0.170 & $\mathrm{n} / \mathrm{a}$ \\
\hline
\end{tabular}

${ }^{a}$ residential location exogenous; density exogenous

${ }^{\mathrm{b}}$ residential location endogenous; density exogenous

${ }^{\mathrm{c}}$ residential location and density endogenous

$\mathrm{n} / \mathrm{a}=$ not available

* Indicates a proportional change

Source: Concas and DeSalvo [7] 


\section{Transit Ozone-Reduction Toolbox: Strategies Evaluated by TRIMMS}

\subsection{Introduction}

Investment in public transportation can provide a cost-effective and efficient means to reduce greenhouse gas emissions (GHG), and FDOT has been actively engaged in identifying GHG reduction strategies for transit [45-47]. Additionally, FDOT developed a GHG baseline for each transit agency in Florida, and research efforts have focused on ozone emission reductions.

One of the objectives of this study was to ensure that the TRIMMS model can be used to assess most of the ozone-reduction strategies identified by the Transit Ozone-Reduction Toolbox developed by FDOT [3]. This section provides a summary of the ozone-reduction strategies considered by the Toolbox and discusses the use of TRIMMS to evaluate their benefits.

\subsection{Using TRIMMS to Evaluate Ozone-Reduction Strategies}

When prioritizing transit capital investment strategies geared at emission reductions, focusing on ozone emissions can result in a limited evaluation of some scenarios or strategies. For example, while investments in bus rapid transit might represent a cost-efficient solution due to lower capital and infrastructure costs, it might prove less efficient compared to light rail transit in terms of emission reduction attainment when the whole range of pollutants is taken into consideration.

Evaluation tools that focus only on ozone reduction strategies may underestimate the relevance of other criteria pollutants. Transit services, such as bus transit and bus rapid transit usually rely on diesel fuel, which produces other health-affecting pollutants, such as particulate matter (PMX). Fine inhalable particles tend to have the greatest impact on human health as they pass deep into the lungs, thus leading to severe respiratory diseases.

TRIMMS allows evaluating a wide range of emission reduction strategies by producing detailed emission change estimates for several emission pollutants, differentiating between emissions changes from reduced single occupancy vehicle travel and changes in transit emissions generated by increased provision of transit services.

\subsection{List of Strategies Evaluated by TRIMMS}

The Toolbox provides a comprehensive list of ozone-reduction strategies that transit agencies can pursue based on the need to reduce ozone emissions. Table 5 shows the full list of ozone- 
reduction strategies listed in the Toolbox, and those strategies that can be evaluated by TRIMMS.

As detailed in the previous section, TRIMMS evaluates a wide range of TDM strategies. The list of strategies listed in the Toolbox coincide with many of this strategies, specifically the promotion of employer-based commuter programs, the implementation of subsidies and fare discounts to incentivize the use of alternative modes, such as transit, carpooling and vanpooling. In addition, under this upgrade, TRIMMS now estimates relevant land use strategies, like policies that increase gross population density levels, reduce home-to-work distances, or investments in transit-oriented development stations. TRIMMS can evaluate these strategies when implemented in combination, providing estimates that are not cumulative. This is consistent with the Toolbox approach. For example, in evaluating the impact of fare reductions and simplifications, the Toolbox recommends combining fare reduction with marketing promotion strategies to achieve the greatest impacts. 
Table 5. Transit Ozone-Reduction Strategies Evaluated by TRIMMS

\begin{tabular}{|c|c|c|c|c|}
\hline \multicolumn{5}{|c|}{ Evaluated by } \\
\hline Strategy & Description & TRIMMS? & How? & At What Level? \\
\hline \multicolumn{5}{|l|}{ Transit Direct Improvement } \\
\hline Convenient Fare Collection & Improving convenience of pass sales & $\mathbf{N}$ & $\mathrm{N} / \mathrm{A}$ & $\mathrm{N} / \mathrm{A}$ \\
\hline Fare Reductions or Simplifications & $\begin{array}{l}\text { Fare subsidies or streamlining of fare collection } \\
\text { between systems and modes }\end{array}$ & $\mathbf{Y}$ & $\begin{array}{l}\text { Using the Financial and Pricing Strategies } \\
\text { module and changing transit fare costs }\end{array}$ & Employer worksite or region \\
\hline Increase in Transit Service & $\begin{array}{l}\text { Increasing the amount of service provided. } \\
\text { This could result in decreased access/travel } \\
\text { times }\end{array}$ & $\mathbf{Y}$ & $\begin{array}{l}\text { Using the Access and Travel Time } \\
\text { Improvements module and changing access } \\
\text { or travel times }\end{array}$ & Employer worksite or region \\
\hline Ridesharing Programs & $\begin{array}{l}\text { Promotion of carpooling and vanpooling. This } \\
\text { could take the form of subsidy to incentivate } \\
\text { usage }\end{array}$ & $\mathbf{Y}$ & $\begin{array}{l}\text { By checking the appropriate options under } \\
\text { the Program Subsidies and Guaranteed Ride } \\
\text { Home modules }\end{array}$ & Employer worksite or region \\
\hline Transit Infrastructure Improvements & $\begin{array}{l}\text { Adding stations or new lines. This can result in } \\
\text { increased service, which reduces distances and } \\
\text { travel times }\end{array}$ & $\mathbf{Y}$ & $\begin{array}{l}\text { By changing before and after transit and } \\
\text { access travel time under the Access and } \\
\text { Travel Time Improvements module }\end{array}$ & Employer worksite or region \\
\hline Vehicle Technology Improvements & Fuel-efficient, alternative fuel fleet purchases & $\mathbf{Y}$ & $\begin{array}{l}\text { By changing fuel efficiency and emission } \\
\text { parameters }\end{array}$ & Employer worksite or region \\
\hline \multicolumn{5}{|l|}{ Indirect Transit Improvements } \\
\hline Transit Marketing & $\begin{array}{l}\text { The promotion of transit use by specific } \\
\text { programs }\end{array}$ & $\mathbf{Y}$ & $\begin{array}{l}\text { Through employer-based marketing efforts in } \\
\text { the Program Marketing module }\end{array}$ & Employer worksite \\
\hline Ozone Reduction Days & $\begin{array}{l}\text { Marketing days when transit fares are free or } \\
\text { reduced in conjunction with ozone-related } \\
\text { events }\end{array}$ & $\mathbf{N}$ & N/A & N/A \\
\hline Guaranteed Ride Home Program & $\begin{array}{l}\text { The provision of emergency rides to ridesharing } \\
\text { and carsharing participants }\end{array}$ & $\mathbf{Y}$ & $\begin{array}{l}\text { By checking the appropriate option in the } \\
\text { Guaranteed Ride Home and Ride Match } \\
\text { module }\end{array}$ & Employer worksite or region \\
\hline Transit Amenities & $\begin{array}{l}\text { The provision of bike racks, shelters, sidewalks, } \\
\text { and other amenities }\end{array}$ & $\mathbf{Y}$ & $\begin{array}{l}\text { by checking the appropriate option in the } \\
\text { Worksite Characteristics module }\end{array}$ & Employer worksite \\
\hline \multicolumn{5}{|l|}{ Employer-Based Commuter Programs } \\
\hline Live Near Your Work Campaigns & $\begin{array}{l}\text { Implementive incentive programs to encourage } \\
\text { commuters to live closer to work }\end{array}$ & $\mathbf{Y}$ & $\begin{array}{l}\text { By using land-use controls and changing } \\
\text { distance to the nearest employment } \\
\text { subcenter to gauge transit responsiveness to } \\
\text { incremental changes }\end{array}$ & Region wide evaluation only \\
\hline Employer-Sponsored Commute Programs & $\begin{array}{l}\text { Providing marketing and support of employer- } \\
\text { based incentive programs }\end{array}$ & $\mathbf{Y}$ & By checking all relevant options in the model & Employer worksite or region \\
\hline Trip Reduction Ordinances & $\begin{array}{l}\text { Ordinances requiring employers to reduce } \\
\text { employee trips }\end{array}$ & $\mathbf{Y}$ & By checking all relevant options in the model & Employer worksite or region \\
\hline
\end{tabular}


Table 5. Transit Ozone-Reduction Strategies Evaluated by TRIMMS, Continued

\begin{tabular}{|c|c|c|c|c|}
\hline \multicolumn{5}{|c|}{ Evaluated by } \\
\hline Strategy & Description & TRIMMS? & How? & At What Level? \\
\hline \multicolumn{5}{|l|}{ ITS Programs } \\
\hline Advanced Public Transportation System & $\begin{array}{l}\text { Improving passenger information through } \\
\text { advanced systems, which improve travel } \\
\text { schedule and travel time reliability }\end{array}$ & $\mathbf{Y}$ & $\begin{array}{l}\text { By assuming changes in transit access and } \\
\text { travel times and using the Access and } \\
\text { Travel Time Improvements module }\end{array}$ & Employer worksite or region \\
\hline Transit Preferential Treatments & Transit signal priority or queue jumps & $\mathbf{Y}$ & \begin{tabular}{|l|} 
By assuming changes in transit access and \\
travel times and using the Access and \\
Travel Time Improvements module
\end{tabular} & Employer worksite or region \\
\hline \multicolumn{5}{|l|}{ Improved Connections to Other Modes } \\
\hline Pedestrian and Bicycle Connectivity & $\begin{array}{l}\text { Improving connectivity across modes } \\
\text { supportive of transit use }\end{array}$ & $\mathbf{Y}$ & $\begin{array}{l}\text { By changing walking distances to closest } \\
\text { stations in the Land Use Controls module } \\
\text { or by checking the provision of bicycle } \\
\text { amenities at workplace option in the } \\
\text { Worksite Characteristics module } \\
\end{array}$ & Employer worksite or region \\
\hline Bicycle Amenities at Transit Facilities & $\begin{array}{l}\text { The provision of bicycle amenities at transit } \\
\text { stops }\end{array}$ & $\mathbf{Y}$ & $\begin{array}{l}\text { By using the Worksite Characteristics } \\
\text { module and checking appropriate options }\end{array}$ & Employer worksite \\
\hline Bicycle Information Programs & $\begin{array}{l}\text { Marketing the use of bicycle as an } \\
\text { alternative mode }\end{array}$ & $\mathbf{Y}$ & $\begin{array}{l}\text { By using the Program Marketing module } \\
\text { and checking the appropriate employer- } \\
\text { based marketing efforts }\end{array}$ & Employer worksite \\
\hline Park and Ride Lots & $\begin{array}{l}\text { Provision of park and ride lots to connect } \\
\text { transit to other modes }\end{array}$ & $\mathbf{Y}$ & $\begin{array}{l}\text { By clicking the TOD stop option in the } \\
\text { Land Use Controls module }\end{array}$ & Employer worksite or region \\
\hline Carsharing Programs & $\begin{array}{l}\text { Provision of carsharing where participants } \\
\text { can jointly rent vehicles for work or non- } \\
\text { work travel }\end{array}$ & $\mathbf{N}$ & $\mathrm{N} / \mathrm{A}$ & N/A \\
\hline
\end{tabular}

Source: Transit Ozone-Reduction Strategies Toolbox [3] and CUTR TRIMMS Model 


\subsection{Comprehensive Evaluation of Emission Reduction Strategies}

The potential to employ TRIMMS to evaluate the emission reduction strategies of Table 5 for policy assessment is best represented by the recently published report of the Transportation and Regional Programs Divisions (TRDP) of the EPA's Office of Transportation and Air Quality (OTAQ) [1]. OTAQ provides analysis, guidance and technical assistance on transportation policy and programs effects on mobile source emissions and air quality to federal, state, and local agencies [48].

The OTAQ study is intended to provide support for national policy-level assessments of transportation control measures (TCM) listed in the Clean Air Act and other strategies, such as road pricing and smart growth, to reduce emissions and vehicle miles of travel (VMT).

The study considered various strategies listed in Table 5, such as TDM initiatives, land use policies, transit-related strategies, and parking and road pricing to produce future travel and emission reduction scenarios by varying the level of intensity of policy measures. The OTAQ analysis used the TRIMMS mode to estimate the national potential reductions in VMT under a variety of scenarios through the period 2010-2050. Table 6 reports the findings from this study, showing that the greatest benefits in emission reductions are achieved by effectively combining several strategies.

The OTAQ study shows that TRIMMS can be used to conduct policy assessment to assist local and regional agencies in selecting the most cost-effective and beneficial emission reduction strategies. As discussed in the next chapter, TRIMMS can be further extended to include the evaluation of strategies that were not analyzed in the EPA report due to the limitations of the previous version of TRIMMS. 
Estimating Costs and Benefits of Emissions Reduction Strategies for Transit by Extending the TRIMMS Model

Table 6. Emission Reductions For Selected Pollutants: EPA National TCM Policy Evaluation

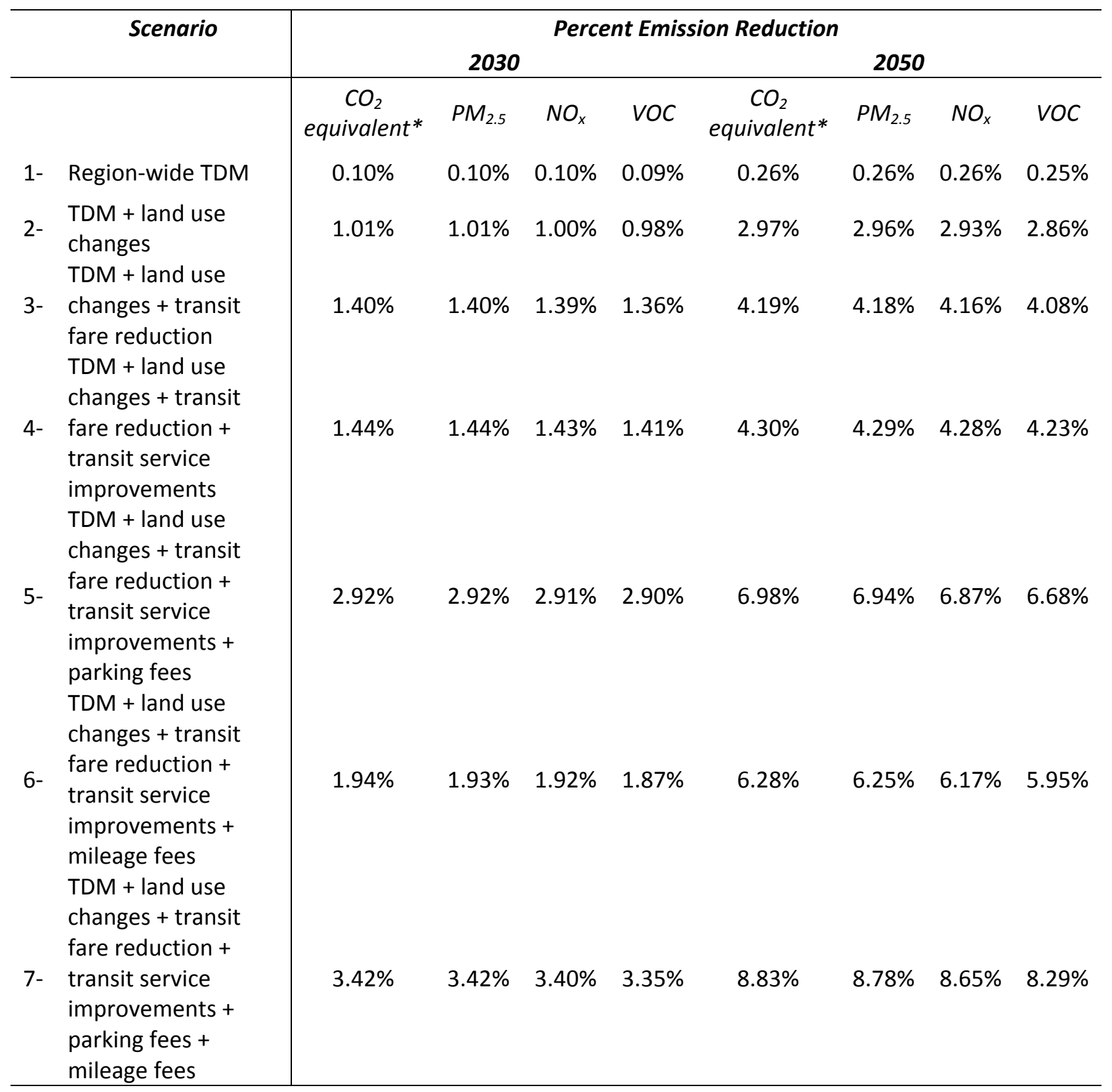

$* \mathrm{CO}_{2}$ equivalent $=\left[\mathrm{CO}_{2}+21 \times\left(\mathrm{CH}_{4}\right)+310 \times\left(\mathrm{N}_{2}\right)\right]$

Source: Transportation and Regional Program Division, Office of Transportation and Air Quality, U.S. Environmental Protection Agency [1] 


\section{Conclusions}

Investment in public transportation can provide a cost-effective and efficient means to reduce GHG emission, with FDOT leading the effort in identifying GHG reduction strategies for transit [45-47]. Additionally, FDOT developed a GHG baseline for each transit agency in Florida, and research efforts have focused on ozone emission reductions. When prioritizing transit capital investment strategies geared at emission reductions, focusing on ozone emissions can result in a limited evaluation of some scenarios or strategies. For example, while investments in bus rapid transit might represent a cost-effective solution due to lower capital and infrastructure costs, it might prove less efficient compared to light rail transit in terms of emission reduction attainment when the whole range of pollutants is taken into consideration. Evaluation tools that focus only on ozone reduction strategies may underestimate the relevance of other criteria pollutants. Transit services such as bus transit and bus rapid transit usually rely on diesel fuel, which produces other health-affecting pollutants, such as fine particulate matter. Fine inhalable particles tend to have the greatest impact on human health as they pass deep into the lungs, thus leading to severe respiratory diseases.

This study extended the TRIMMS model for assessing the full benefits and costs associated with the implementation of ozone-reduction transit investment strategies and to account for a broader spectrum of emission pollutants.

This research resulted in a substantial upgrade to TRIMMS and improvement of its estimation capabilities, leading to TRIMMS 3.0. To meet the objectives of this research, the new version now estimates a wider range of emission pollutants and incorporates a new module that evaluates the impact of land use strategies on transit patronage levels. In addition, using feedback from a pool of current users and TDM experts, TRIMMS underwent major interface and usability improvements.

TRIMMS uses the emission inventory of the newly developed EPA MOVES2010a, which makes it suitable to run official SIPs and regional emissions analyses for transportation conformity purposes.

TRIMMS enables FDOT, transit agencies, MPOs and local communities to quickly estimate changes in emissions and the societal benefits in changes in travel behavior in a similar manner as highway cost-benefit analyses. Practitioners can conduct cost-benefit assessments for most of the strategies identified in the FDOT-sponsored Transit Ozone-Reduction Strategies Toolbox without the cost and expertise required by more sophisticated models.

During the preparation of this report and the update to TRIMMS 3.0, EPA released a report that analyzes the potential role travel efficiency strategies can play in helping reduce criteria air pollutants and GHG emissions at the national level [1]. EPA is also releasing a second report that will provide guidance to states and local government considering similar assessments. The 
studies made extensive use of the TRIMMS model. As part of the findings, EPA concluded that additional research is needed to understand the impact of congestion pricing strategies in impacting travel behavior and reducing criteria air pollutants. In particular, the EPA report points to the necessity of estimating the impacts associated with land use strategies and congestion pricing techniques. While this new version of TRIMMS includes the land use module, it needs to expand its capacity in evaluating the impact of congestion pricing strategies. A future extension of the model would incorporate a module capable of estimating changes in average traveling speed in response to pricing strategies, as well as evaluating the benefits associated with travel time reliability changes.

Some users of TRIMMS 2.0 requested a version that estimates the impacts of these strategies in terms of benefits to businesses. For example, they want to know what is the effect of a telework and compressed workweek programs on productivity, overhead expenses, employee turnover, and absenteeism. This could be another future modification. 


\section{References}

1. U.S. Environmental Protection Agency, Potential Changes in Emissions Due to Improvements in Travel Efficiency - Final Report, 2011, Transportation and Regional Programs Division, Office of Transportation and Air Quality.

2. Winters, P.L., et al., Incorporating Assumptions for TDM Impacts in a Regional Travel Demand Model, 2010, Washington State Department of Transportation.

3. Florida Department of Transportation, Transit Ozone-Reduction Strategies Toolbox, 2010.

4. Concas, S. and P.L. Winters, Economics of Transportation Demand Management (TDM), 2007, National Center for Transit Research at the Center for Urban Transportation Research: Tampa.

5. Concas, S. and P.L. Winters, Quantifying the Net Social Benefits of Vehicle Trip Reductions: Guidance for Customizing the TRIMMS Model, 2009, National Center for Transit Research at the Center for Urban Transportation Research: Tampa.

6. Kuzmyak, J.R., et al., Procedures Manual for the COMMUTER Model v2.0, 2005, U.S. Environmental Protection Agency, Office of Transportation and Air Quality.

7. Concas, S. and J.S. DeSalvo, Integrating Transit and Urban Form, 2008, Center for Urban Transportation Research.

8. Murphy, J.J. and M.A. Delucchi, A Review of the Literature on the Social Cost of Motor Vehicle Use in the United State. Journal of Transportation and Statistics, 1998. 1(1): p. 15-42.

9. Litman, T., Air Pollution Costs, in Transportation Cost and Benefit Analysis - Techniques, Estimates and Implications, 2009, Victoria Transport Policy Institute: Victoria.

10. Litman, T., Energy Conservation and Emission Reduction Strategies, in TDM Encyclopedia, V.T.P. Institute, Editor, 2008, Victoria Transport Policy Institute: Victoria.

11. Bernstein, L., et al., Climate Change 2007: Synthesis Report, in An Assessment of the Intergovernmental Panel on Climate Change, 2007, Intergovernmental Panel on Climate Change.

12. Greenhouse Gas Emission. Climate Change, 2009 [cited 2009 January, 2009]; Available from: http://www.epa.gov/climatechange/emissions/index.html.

13. U.S. Environmental Protection Agency, Greenhouse Gas Emissions for the U.S. Transportation Sector 1990-2003, 2006, Office of Transportation and Air Quality: Fairfax.

14. Delucchi, M., The Social-Cost Calculator (SCC): Documentation of Methods and Data, and Case Study of Sacramento, 2005, Institute of Transportation Studies.

15. Household Median Income Table B19013. American Community Survey 3-Year Estimates 20072009, March, 2009; Available from: http://factfinder.census.gov.

16. Consumer Price Index - All Urban Consumers, 2009, Bureau of Labor Statistics.

17. $\mathrm{OMB}$, Guidelines and Discount Rates for Benefit-Cost Analysis of Federal Programs, O.o.M.a. Budget, Editor 2009, Office of Management and Budget: Washington, D.C.

18. Sinha, K.C. and S. Labi, Impacts on Energy Use. Transportation decision making: principles of project evaluation and programming, 2007: John Wiley \& Sons.

19. HERS-ST Technical Report, in HERS -ST Highway Economic Requirements System-State Version, 2005, Federal Highway Administration.

20. Gasoline Prices by Formulation, Grade, Sales Type, 2009, Energy Information Administration.

21. Fuel Efficiency. National Transportation Statistics 2010 [cited 2010]; Available from: http://www.bts.gov/publications/national transportation statistics/.

22. Delucchi, M., The Annualized Social Cost of Motor-Vehicle Use in the U. S., 1990-1991: Summary of Theory, Data, Methods, and Results, in The annualized social cost of motor-vehicle use in the United States, based on 1990-1991 Data, 1996, Institute of Transportation Studies.

23. U.S. Census, U.S. Census Summary File 3 (SF3), 2000. 
24. Retail Establishments, County Business Patterns, 2010; Available from: http://censtats.census.gov/cgi-bin/msanaic/msasect.pl.

25. Hourly Wages: May 2010, Metropolitan and Nonmetropolitan Area Occupational Employment and Wage Estimates; Available from: http://www.bls.gov/oes/current/oessrcma.htm.

26. Crash rates by KABCO severity class. Fatality Analysis Reporting System; Accessed Nov. 2011, Available from: http://www-fars.nhtsa.dot.gov/Main/index.aspx.

27. Concas, S. and A. Kolpakov, Synthesis of Researh on the Value of Time and Value of Reliability of Travel Time, 2009, National Center for Transit Research at the Center for Urban Transportation Research: Tampa.

28. Blincoe, L.J., et al., The Economic Impact of Motor Vehicle Crashes 2000, N.H.T.S. Administration, Editor, 2002, U.S. Department of Transportation: Washington, D.C.

29. Fatality Analysis Reporting System, 2011; Available from: http://www.nhtsa.gov/FARS.

30. Vehicle miles of travel by roadway type. Highway Statistics Series, 2010; Available from: http://www.fhwa.dot.gov/policyinformation/statistics/2010/.

31. MOVES (Motor Vehicle Emission Simulator). Modeling and Inventories, 2010, EPA-420-B-10-023; Available from: http://www.epa.gov/otaq/models/moves/.

32. Transportation Planning and Conformity Requirements. Policy Guidance, 2011 [cited 2011 October 2011]; Available from: http://www.epa.gov/otaq/stateresources/transconf/policy.htm.

33. Tol, R.S.J., The marginal damage of carbon dioxide emissions: an assessment of the uncertainties. Energy Policy, 2005. 34: p. 2064-2074.

34. Average Carbon Dioxide Emissins Resulting from Gasoline and Diesel Fuel, U.S. E.P.A. Office of Technology Assessment Quality, Editor, 2005, U.S. Environmental Protection Agency: Fairfax.

35. Delucchi, M. and S.-L. Hsu, The external damage cost of noise emitted from motor vehicles. Journal of Transportation and Statistics, 1998. 1(3): p. 1-25.

36. Litman, T., Noise Costs, in Transportation Cost and Benefit Analysis - Techniques, Estimates and Implications, V.T.P. Institute, Editor, 2009, Victoria Transport Policy Institute: Victoria.

37. Paulley, N., et al., The Demand for Public Transport: The Effects of Fares, Quality of Service, Income and Car Ownership. Transport Policy, 2006. 13(13): p. 295-306.

38. McCollom, B.E. and R.H. Pratt, Chapter 12 - Transit Pricing and Fares, in TCRP Report 95, T.C.R. Program, Editor, 2004, Federal Transit Administration: Washington D.C.

39. Litman, T., Transit Price Elasticities and Cross-Elasticities. Journal of Public Transportation, 2004. 7(2): p. 37-58.

40. Litman, T., Transportation Elasticities, in Transportation Cost and Benefit Analysis - Techniques, Estimates and Implications, V.T.P. Institute, Editor, 2008, Victoria Transport Policy Institute: Victoria.

41. Hymel, K.M., K.A. Small, and K.V. Dender, Induced demand and rebound effects in road transport. Transportation REsearch Part B: Methodological, 2010. 44(10): p. 1220-1241.

42. Concas, S., P.L. Winters, and F. Wambalaba, Fare Pricing Elasticity, Subsidies, and Demand for Vanpool Services. Transportation Research Record, 2005(1924): p. 215-223.

43. Holmgren, J., Meta Analysis of Public Transport Demand. Transportation Research Part A, 2007(41): p. 1021-1035.

44. Concas, S. and N. Nayak, Meta-Analysis of Parking Pricing Elasticities, in Transportation Research Board 91st Annual Meeting, 2011: Washington D.C.

45. Hillsman, E.L., F. Cevallos, and T. Sandos, Conserve by Transit II: Carbon Footprints of Florida's Public Transportation Agencies, 2011, Florida Department of Transportation.

46. Hendricks, S.J., E.L. Hillsman, and A. Stuart, Conserve by Transit II: Carbon Footprints of Florida's Public Transportation Agencies (CFIT), 2010, Florida Department of Transportation.

47. "Transit/Environment." Plan for Transit; Available from: http://planfortransit.com/transitenvironment/. 
Estimating Costs and Benefits of Emissions Reduction Strategies for Transit by Extending the TRIMMS Model

48. Additional State and Local Transportation Resources can be found at: http://www.epa.gov/oms/stateresources/policy/. 
Estimating Costs and Benefits of Emissions Reduction Strategies for Transit by Extending the TRIMMS Model

\section{Appendices}




\section{A.1 Constant Elasticity of Substitution Trip Demand Functions}

TRIMMS predicts mode share and VMT changes brought about by TDM initiatives affecting the cost of travel by using constant elasticity of substitution trip demand functions. These functions estimate changes from baseline trip demands, taking into account user responsiveness to changes in pricing and travel times.

The following example is designed to provide a better understanding of the relationship between price and travel time elasticities and how these relate to travel behavior. We assume that there are two modes, auto and transit; and, that the trip demand functions depend solely on fare costs and travel times. Let us assume the following travel demand function for auto:

$$
d_{i}=A P_{i}^{\epsilon_{i}^{P}} T_{i}^{\epsilon_{i}^{T}} T_{j}^{\epsilon_{i, j}^{T}}
$$

Where:

$d_{i}=$ demand for auto travel, measured in person trips per day

$j=$ transit mode

$A=$ scale parameter

$P_{i}=$ car travel fuel price

$T_{i}=$ car travel time

$T_{j}=$ transit travel time

$\epsilon_{i}^{P}=$ car trip cost elasticity

$\epsilon_{i}^{T}=$ car travel time elasticity

$\epsilon_{i, j}^{T}=$ car travel time cross-elasticity with respect to transit travel time

We specify the demand function using a constant-elasticity demand function because of its wide empirical application in the estimation of travel demand elasticities and for its ease of analytical tractability. ${ }^{3}$

\footnotetext{
${ }^{3}$ The demand curves usually employed and depicted in graphs are linear demand curves, which have the property that price elasticity declines as we move down the demand curve. Not all demand curves have this property, however; on the contrary, there are demand curves for which price elasticity can remain constant or even rise with movements down the demand curve. The constant-elasticity demand curve is the name given to a demand curve for which elasticity does not vary with price and quantity. Whereas the linear demand curve has the general form $P=a-b Q$, the constant-elasticity demand curve is instead written as:

$$
P=\frac{k}{Q^{\frac{1}{\eta}}}
$$

Where $k$ and $\eta$ are positive numbers that determined the shape of the curve.
} 
The price elasticity of a car measures the percent reduction in trips due to a one percent increase in its price. The travel time elasticity of demand measures the percent reduction in trips due to a one percent increase in travel time. Finally, the car travel time cross elasticity with respect to transit travel time measures the percent reduction in trips due to a one percent decrease in transit travel time. We assume that car and transit are substitutes. ${ }^{4}$

Now, for initial values of fuel price, time and trips, denoted by subscript zeros, the auto trip demand is:

$$
d_{i 0}=A P_{i 0}^{\epsilon_{i}^{P}} T_{i 0}^{\epsilon_{i}^{T}} T_{j 0}^{\epsilon_{i, j}^{T}}
$$

Solving for $A$ in (A.2) and substituting the results back into (A.1), we can eliminate the scale parameter $A$ and ensure that the demand function passes through the point $\left(d_{0}, P_{0}, T_{0}\right)$. The resulting equation is:

$$
d_{i}=d_{i 0}\left(\frac{P_{i}}{P_{i}}\right)^{\epsilon_{i}^{P}}\left(\frac{T_{i}}{T_{i}}\right)^{\epsilon_{i}^{T}}\left(\frac{T_{j}}{T_{j}}\right)^{\epsilon_{i, j}^{T}}
$$

Then, for a given change in trip costs and travel times, the new number of vehicle trips is obtained by substituting the new costs and travel times into equation (A.3), giving:

$$
d_{i}=d_{i 0}\left(\frac{P_{i 1}}{P_{i 0}}\right)^{\epsilon_{i}^{P}}\left(\frac{T_{i 1}}{T_{i 0}}\right)^{\epsilon_{i}^{T}}\left(\frac{T_{j 1}}{T_{j 0}}\right)^{\epsilon_{i, j}^{T}}
$$

Finally, what we are interested in is the change in the number of vehicle trips, which is given by:

$$
\Delta d_{i}=d_{i 0}\left[\left(\frac{P_{i 1}}{P_{i 0}}\right)^{\epsilon_{i}^{P}}\left(\frac{T_{i 1}}{T_{i 0}}\right)^{\epsilon_{i}^{T}}\left(\frac{T_{j 1}}{T_{j 0}}\right)^{\epsilon_{i, j}^{T}}-1\right]
$$

This last formula constitutes the approach to model the change in demand brought about by program or policies affecting the perceived cost of travel, both monetary and non-monetary. Equation (A.5) can be simplified or expanded to include additional cost factors and to comprise cross relationships with one or more modes.

\footnotetext{
${ }^{4}$ Two goods are considered substitutes if the increase in the price of one determines an increase in the demand for the other. Two goods are considered complements if the increase in the price of one good causes a decrease in the demand for both goods (e.g., coffee and cream). The relationship is further refined by considering perfect versus less-than-perfect substitution and complement.
} 


\section{Advantages and Constraints}

There are different ways of providing a simple, yet powerful and robust approach to estimating the impacts of alternative strategies at a sketch planning level. The constant elasticity of demand approach proposed requires basic information on the cost and time components of modal trips and on the initial mode share. By entering the impact on the generalized cost of travel of a given policy or program, the model estimates the impact on the final mode shares. These data requirements are described in greater detail in this report.

The model estimates impacts on travel behavior in a synergistic fashion. That is, the model allows the simultaneous impact assessment of several TDM policies or strategies, where the final total impacts are greater than the sum of the impact of each individual strategy. In addition, the constant elasticity of demand equation (A.5) assures that impacts are assessed in a multiplicative, rather than an additive, fashion avoiding impacts overestimation. For example, if one strategy (e.g., a transit subsidy) reduces SOV use by 5 percent and another strategy, say parking pricing, reduces SOV use by an additional 7 percent, the total combined effect is a 11.5 percent reduction (calculated as $100 \%$ - [95\% x 93\%]), rather than a 12 percent reduction (linearly calculated as $7 \%+5 \%$ ).

Another advantage of the model is that it allows program evaluation based on incremental impacts. For example, under the constant elasticity demand framework the congestion reduction benefits of a shift from SOV to transit is the difference in congestion impacts between SOV and transit travel. Using a base case approach (a scenario where a policy or program is not implemented), the model estimates the net benefits of shifting from SOV to alternative modes. Also, the model permits distinguishing between peak and off-peak impact estimation at an urban area level.

One of the constraints related to the use of elasticities relates to timeframes employed when empirically estimating their values. Applied work generally employs short and medium terms (3-5 years), thus tending to underestimate the full, long term effects of price and service changes. In other terms, increasing (reducing) a transit fare has more negative (positive) effects than what is generally predicted by most models. The constant elasticity of a demand model is best suited for strategies that directly affect the generalized cost of driving, and a set of TDM strategies, such as: 
- Parking pricing

- Modal subsidies

- Pay as the user go schemes

- Transit service improvements

- Other interventions affecting the cost of driving or modal access and travel time

These strategies often integrate both incentives and disincentives. The latter are usually defined as "sticks" and comprise actions geared at directly influencing the cost of driving, such as increased auto user charges, parking pricing, and traffic calming. 


\section{A.2 Program Support Evaluation}

Program support strategies that are designed to enhance voluntary behavior changes are usually defined as "carrots" and usually consist of measures geared either at increasing the knowledge of alternative modes and programs or at internalizing some of the costs associated to driving that would otherwise be borne by others. Examples of soft program initiatives include:

- Travel Planning

- Advertising

- Flexible Work Hours

- Telecommuting

- Guaranteed Ride Home Programs

- Discount for Walking and/or Cycling Gear

Although these programs do not directly affect the cost of using a mode, they tend to impact travel behavior when part of a program consists of hard measures. Generally, it is not possible to directly estimate change in travel behavior from these TDM strategies.

To evaluate the impact of program support strategies on travel behavior, TRIMMS relies on an econometric analysis of the relationship between hard and soft programs of the Washington State Department of Transportation Trip Reduction Program. We first prepared a dataset covering the period 1995 to 2005. The data reports information on worksite characteristics, such as firm size and industry type, employee mode share, and information of TDM programs.

We specify a regression equation where each of employer support programs enters into an empirical equation estimating the change in ridership as an explanatory variable in a context of interaction with hard programs. ${ }^{5}$ The regression equation takes the form:

$$
y=\beta_{0}+\beta_{1} x_{1}+\beta_{2} x_{2}+\cdots+\beta_{k} x_{k}+\epsilon
$$

Where $y$ is the dependent variable, in this case vehicle trip rate at worksite; $x_{1}, x_{2}, \ldots x_{k}$ are explanatory variables (soft and hard program policies, firm characteristics, other controls); and $\epsilon$ is a stochastic or error term. Equation (A.7) can include squared terms to acknowledge nonlinear relationships, and interaction terms between the response variables.

We analyzed the dataset and employed factor analysis to reduce the number of explanatory variables to improve model prediction power. ${ }^{6}$ We use these results to specify a predictive

\footnotetext{
${ }^{5}$ The model herein proposed to build upon previous work conducted by CUTR in estimating worksite trip reduction tables [30].

${ }^{6}$ Factor analysis is a statistical technique that reduces several variables that are correlated into a smaller set of new, uncorrelated and meaningful variables.
} 
model that allows for interaction between qualitative variables was chosen as the one with the higher predictive power. ${ }^{7}$

\footnotetext{
${ }^{7}$ In a regression model, qualitative variables take the form of dummy variables. These are explanatory variables that take the value of 1 if present or take the value 0 if absent. For example, dummy variables can be used to estimate main effects due to the presence or the absence of a given program promotion initiative, a given subsidy, and the offering or not of a guaranteed ride home program. Furthermore, very often these initiatives are linked to each other in an interactive fashion. An interaction model has to be built to analyze a main effect model.
} 


\section{A.3 Data Sources}

- Freeway Speed (2009): Exhibit A-8, Schrank, D., Lomax, T., and Turner, S., Urban Mobility Report 2010, Texas Transportation Institute, December 2010 http://mobility.tamu.edu/ums/

- Arterial Speed (2009): Exhibit A-8, Schrank, D., Lomax, T., and Turner, S., Urban Mobility Report 2010, Texas Transportation Institute, December 2010 http://mobility.tamu.edu/ums/

- Household Income (2007-2009): Table B19013 Median household income in the past 12 months (in 2009 inflation-adjusted dollars), 2007-2009 American Community Survey 3-Year Estimates http://factfinder2.census.gov/faces/nav/jsf/pages/index.xhtml

- Population Density: G001 Geographic Identifiers, 2010 Demographic Profile Data, U.S. Census Bureau http://factfinder2.census.gov/faces/nav/isf/pages/index.xhtml

- Housing Data: G001 Geographic Identifiers, 2010 Demographic Profile Data, U.S. Census Bureau http://factfinder2.census.gov/faces/nav/jsf/pages/index.xhtml

- Mode Share (Auto, Ride, Van, Transit, Walk, etc): Table B08301, Means of transportation to work Universe: Workers 16 Years and over, 2007-2009 American Community Survey 3 - Year Estimates http://factfinder2.census.gov/faces/nav/isf/pages/index.xhtml

- Occupation (Agriculture, Construction, Transportation, etc): Table B24050, Industry by Occupation for the Civilian Employed Population 16 years and over Universe: Civilian Employed Population 16 years and over, 2007-2009 American Community Survey 3 Year Estimates http://factfinder2.census.gov/faces/nav/jsf/pages/index.xhtml

- Geographic Area: G001 Geographic Identifiers, 2010 Demographic Profile Data, U.S. Census Bureau http://factfinder2.census.gov/faces/nav/isf/pages/searchresults.xhtml?refresh=t

- Retail Establishments: 2009 MSA Business Patterns (NAICS), U.S. Census Bureau http://censtats.census.gov/cgi-bin/msanaic/msasect.pl

- Vehicle per Household: U.S. Department of Transportation, Federal Highway Administration, 2009 National Household Travel Survey. http://nhts.ornl.gov/tables09/ae/work/Job18443.html

- Average Vehicle Occupancy: U.S. Department of Transportation, Federal Highway Administration, 2009 National Household Travel Survey. http://nhts.ornl.gov/tables09/ae/work/Job18444.html 
- Annual Transit Trips: U.S. Department of Transportation, Federal Highway Administration, 2009 National Household Travel Survey. http://nhts.ornl.gov/tables09/ae/work/Job18447.html

- Per Capita Personal Income: 2009, Bureau of Economic Analysis, U.S. Department of Commerce http://www.bea.gov/iTable/iTable.cfm?reqid=70\&step=1\&isuri=1\&acrdn=3

- Home to Work Distance: U.S. Department of Transportation, Federal Highway Administration, 2009 National Household Travel Survey. http://nhts.ornl.gov/tables09/ae/work/Job18450.html

- Average Trip Length (Car, Van, Motorcycle, etc): U.S. Department of Transportation, Federal Highway Administration, 2009 National Household Travel Survey. http://nhts.ornl.gov/tables09/ae/work/Job18445.html

- Walking Distance to Public Transit: U.S. Department of Transportation, Federal Highway Administration, 2009 National Household Travel Survey. http://nhts.ornl.gov/tables09/ae/work/Job18451.html

- Hourly Wages: May 2010 Metropolitan and Nonmetropolitan Area Occupational Employment and Wage Estimates, Bureau of Labor Statistics, U.S. Department of Labor http://www.bls.gov/oes/current/oessrcma.htm 